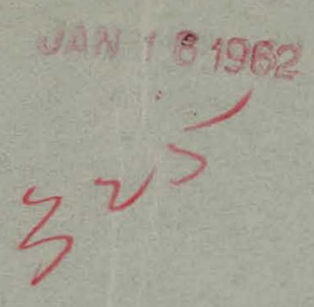

\author{
ORNL-3169 \\ UC-34 - Physics \\ TID-4500 (16th ed., Rev.)
}
CALCULATION OF THE PULSE-HEIGHT RESPONSE OF NaI(T $\ell)$ SCINTILLATION COUNTERS
C. D. Zerby
H. S. Moran

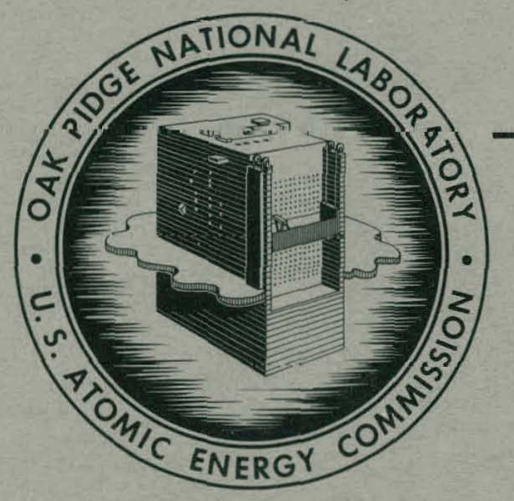

OAK RIDGE NATIONAL LABORATORY

$$
\text { operated by }
$$

UNION CARBIDE CORPORATION

for the

U.S. ATOMIC ENERGY COMMISSION 


\section{DISCLAIMER}

This report was prepared as an account of work sponsored by an agency of the United States Government. Neither the United States Government nor any agency Thereof, nor any of their employees, makes any warranty, express or implied, or assumes any legal liability or responsibility for the accuracy, completeness, or usefulness of any information, apparatus, product, or process disclosed, or represents that its use would not infringe privately owned rights. Reference herein to any specific commercial product, process, or service by trade name, trademark, manufacturer, or otherwise does not necessarily constitute or imply its endorsement, recommendation, or favoring by the United States Government or any agency thereof. The views and opinions of authors expressed herein do not necessarily state or reflect those of the United States Government or any agency thereof. 


\section{DISCLAIMER}

Portions of this document may be illegible in electronic image products. Images are produced from the best available original document. 


\section{Printed in USA. Price $\$ 1.25$. Available from the}

Office of Technical Services

Department of Commerce

Washington 25, D.C.

\section{LEGAL NOTICE}

This report was prepared as an account of Government sponsored work. Neither the United States, nor the Commission, nor any person acting on behalf of the Commission:

A. Makes any warranty or representation, expressed or implied, with respect to the accuracy, completeness, or usefulness of the information contained in this report, or that the use of any information, apparatus, method, or process disclosed in this report may not infringe privately owned rights; or

B. Assumes any liabilities with respect to the use of, or for damages resulting from the use of any information, apparatus, method, or process disclosed in this report.

As used in the above, "person acting on behalf of the Commission" includes any employee or. contractor of the Commission, or employee of such contractor, to the extent that such employee or contractor of the Commission, or employee of such contractor prepares, disseminates, or provides access to, any information pursuant to his employment or contract with the Commission, or his employment with such contractor. 
Contract No. W-7405-eng-26

\author{
NEUTRON PHYSICS DIVISION
}

CALCULATION OF THE PULSE-HEIGHT RESPONSE OF $\operatorname{NaI}(T \ell)$ SCINTILLATION COUNTERS

C. D. Zerby and H. S. Moran

\author{
Dater Issued. \\ d)
}

OAK RIDGE NATIONAL IABORATORY

Oak Ridge, Tennessee

operated by

UNION CARBIDE CORPORATION

for the

U.S. ATOMIC ENERGY COMMISSION 


\begin{abstract}
A Monte Carlo calculation to determine the pulse-height response of $\mathrm{NaI}(T \ell)$ scintillation counters to gamma rays is described. Comparisons of several calculations with experiments using 3-in.-dia by 3-in.-high crystals for source energies from 0.32 to $7.48 \mathrm{Mev}$ are presented and show good agreement at large pulse heights. At small pulse heights the calculations underestimate the experimental data and indicate that background radiation can contribute significantly to the experimental results. An extensive series of calculatione are reported for a 3-in.-dia by 3-in.-high crystal using monoenergetic, point isotropic sources placed on the crystal axis $10 \mathrm{~cm}$ from one end. The source energy ranged from 0.1 to $6.0 \mathrm{Mev}$ in this series of calculations.
\end{abstract}




\section{Introduction}

With the increased use of $\mathrm{NaI}(\mathrm{T} l)$ scintillation counters for gamma-ray spectroscopy much time has been devoted to producing pulse-height response spectra from monoenergetic sources for reference ${ }^{l}$ and for use in unfolding complex spectra. Although considerable experimental data are now available, theoretical calculations have become an increasingly important method for supplementing the data in energy regions where monoenergetic sources are not available.

Several Monte Carlo calculations have been reported for crystals of various sizes and source energies. In general, these calculations have not been comprehensive for any particular crystal size and have been additionally restricted to low source energies where secondary energy losses by bremsstrahlung and annihilation radiation are unimportant. ${ }^{2,3}$ The recent work of Miller and Snow ${ }^{4}$ is an exception to the energy restriction. In their calculations they were able to. extend the source energy to $8 \mathrm{Mev}$ by taking secondary losses into account.

The purpose of this paper is to present the results of an extensive series of Monte Carlo calculations for a 3-in. -dia by 3-in.-high NaI(Tl) counter with an isotropic point source of monoenergetic gamma rays on the crystal axis $10 \mathrm{~cm}$ from one end. In this study energy losses by secondary radiation were included and the calculations were performed for source energies from 0.1 to $6.0 \mathrm{Mev}$. The major difference between this calculation and previous ones is that a statistical estimation and a weighting procedure were employed rather than analogue Monte Carlo techniques. The principle advantage of this procedure over analogue Monte Carlo techniques is that of reducing the variance of the estimates for a given sample size, or, alternatively, of reducing the sample size for the same variance.

In Sections 2 and 3, a general description is given of the Monte Carlo calculation that was progranmed for computation on the IBM-704 automatic computing 
machine. A description of the code and its applicability to several alternate source-counter configurations has been presented elsewhere. ${ }^{5}$ Comparisons of some typical calculations with experimental pulse-height response spectra from $\operatorname{NaI}(\mathrm{T} \ell)$ crystals are presented in Section 4. The results of calculations for a 3-in.-dia by 3-in.-high $\mathrm{NaI}(\mathrm{T} \ell)$ crystal are presented in Section 5.

\section{Idealizations and Assumptions}

The basic idealization of the source-counter configuration in the Monte Carlo calculation was that of suspending it in a vacuum. Background effects, which in any case are unique for a particular experimental arrangement, are thus completely eliminated. The difference between calculation and experiment produced by this idealization is expected to be significant in the region of low pulse height and in the region of low response such as in the valley between the total absorption peak and the energy loss spectra for low energy sources.

The response of the crystal was assumed to be proportional to the energy deposited. This is actually not the case for a real crystal which has been shown to have a linear but not proportional response for totally absorpted photons above $70 \mathrm{kev}$. In fact, it is just this effect which has been shown to cause an additional source of line broadening. ${ }^{6}$ However, since the calculations are flrst carried out as if the crystal produced a sharp line in response to the energy deposition and the response spectrum was subsequently spread out by a Gausstan broadening which includes all contributions (see Section 3E), the assumption of proportionality should produce little error in the shape of the curves.

In the transport of the photons through the crystal it was assumed that only photoelectric events, pair production, and Compton scattering could take place. The total cross sections for the latter process was determined from the KleinNishina formula and the others obtained from the tabulated values given by 
Grodstein. 7 Sinc? the photoelectric cross section increases rapidly as the photon energy decreases, photons degraded below $5.11 \mathrm{kev}$ were assumed to be totally absorbed. For Compton events, which are the main source of energy degradation for the photons, the angle and energy of the scattered photons were selected from the differential Klein-Nishina formula for unpolarized primary radiation.

The obvious neglect of Rayleigh scattering in the transport of photons actually amounts to the approximation that the photons scattered by this process are directed straight ahead without energy degradation. The lack of energy degradation is very accurate in this case because of the small energy transmitted to the recolling atom, and the straight ahead approximation, which increases in accuracy as the photon energy increases, is sufficiently valid in the energy range considered in this problem so that errors in the response spectra should be within the statistical accuracy of the calculation.

The charged particles ejected by photon processes play an important part in the determination of the response spectra since they lead to energy loss from the crystal through the secondary radiation they produce. The initial energy of these charged particles, the important parameter for determining the source strength of the bremsstrahlung radiation, was obtained in the following way: for Compton events the electron energy was determined from the kinematics of the collision; for photoelectric events the kinetic energy of the electron was set equal to the energy of the incident photon; and for pair production the excess kinetic energy was distributed between the electron and positron according to the Born approximation distribution by a random selection technique. All these charged particles were assumed to slow down and stop at their point of origin. This can be justified on the basis that the residual path length of a typical particle is small compared with the dimensions of the crystal for energies considered here, ${ }^{8}$ and 
the actual distance from the origin to the stopping point is smaller because of the devious path taken.

The spectrum of the bremsstrahlung radiation emitted by the charged particles shown in Fig. I was taken from a previous calculation which used a continuous slowing-down model and the bremsstrahlung cross section given by the Borm approximation. 9 The direction of emission of the bremsstrahlung radiation was selerter from an isntropic distribution. This was donẹ because electrons at energies considered here diffuse in an almost random direction after they have lost only a small amount of energy; hence, most of the bremsstrahlung photons will be emitted isotropically. Only the direction of the highest energy bremsstrahlung photons will be correlated with the initial direction of the electron since they must be emitted before the electron has lost much energy by deflecting collisions. However, the probability of emitting the high energy photons is relatively small as can be seen in Fig. 1, therefore the assumption of isotropy for all bremsstrahlung radiation should not introduce a serious error.

For the annihilation radiation it was assumed that the positron came to rest before the emission of two photons having one electron rest mass energy each. Actually this is a good approximation at the energies considered here since over $90 \%$ of the positrons will be stopped before annihilation. ${ }^{10}$ As a result of the approximation one of the annihilation photons was selected from an isotropic distribution and the other one given a direction directly opposite to the first to maintain conservation of momentum.

\section{The Computational Procedure}

A. Calculation of the Intrinsic Efficiency

The Monte Carlo calculation was started by determining the direction of incidence of the source radiation on the crystal by systematically sampling the 
Isotropic point source within the cone subtended by the crystal. The probability of making at least one collision in the crystal was then calculated for each sample from the expression $1-\exp \left(-\Sigma_{0} X\right)$, where $\Sigma_{0}$ is the total cross section at the source energy and $X$ is the total path length through the crystal for the particular sample. These quantities were then averaged to yield the intrinsic efflciency.

This procedure actually amounts to a numerical integration because the source was systematically sampled and yields a value of the intrinsic efficiency which has an error of less than $0.1 \%$ in most cases.

B. Calculation of the Analytic Zero Intercept

The pulse-height response spectrum for each source energy was calculated in units of counts per unit energy (pulse height) for one particle incident on the crystal and then normalized for convenience in presentation. The intercept of the unnormalized spectrum with the zero pulse-helght value can actually be calculated very accurately and is quite useful for terminating the curves through the statistical estimates of the spectrum. The method of calculating this end point value can be determined easily if one notes that photons which scatter straight ahead only once before escaping are the only ones that contribute in the limit of zero pulse helght. Thus it can be shown that the average value of the quantities obtained from the expression $(d \Sigma / d E)_{0} X \exp \left(-\Sigma_{0} X\right)$ for each source sanple is the desired quantity. The expression $(d \Sigma / d E)_{0}=2 \pi r_{0}^{2} N m_{0} c^{2} / E_{0}^{2}$, where $N$ is the electron density, $r_{O}$ is the classical electron radius, and $E_{O}$ is the source energy, was obtained from the differential klein-Nishina formula in the limit of straight-ahead scattering. The quantities $\Sigma_{0}$ and $X$ are the same as defined above. This calculation again amounts to a numerical integration because the source was systematially sampled. 
C. Details of the Cascade and Calculation of the Response Spectrum

Once a source photon was permitted to enter the crystal it was never allowed to escape or to be absorbed. To adjust for this unnatural behavior a weight was carried along with each sample photon which represented its survival probability. At every collision point the primary photon was only allowed to scatter and the weight, which was initially set to unity, had to be multiplled by a factor equal to the probability of scattering (the ratio of scattering to total cross section). After the scattering collision the distance, $y$, to the exit surface of the crystal was first calculated and then the randomly selected distance to the next collision was obtained from a truncated exponential distribution so that the distance was always less than or equal to $y$. In this case the relght of sample had to be multiplied by the factor $1-\exp (-\Sigma y)$, where $\Sigma$ is the total cross section at the current energy of the photon, in order to account for the fact that its escape was not allowed.

The principle use of the weights is described below; however, it is appropriate to note here that when the weight decreased below the value 0.001 the history was terminated and the current energy taken to be totally absorbed. This is another way of terminating the hlstory other than when the energy was degraded below $5.11 \mathrm{kev}$ as noted above.

After each scattering collision of the primary radiation the energy of the ejected electron was determined so that the energies of the bremsstrahiung photons emitted in the slowing-down process could be obtained by a systematic sampling procedure from the data presented in F1g. 1. Each of these photons and alI cascade radiation derived from them such as bremsstrahlung and annihilation radiation were followed by an analogue Monte Carlo method to obtain the total energy lost from the crystal. This information was then used in the calculation of the response spectrum. 
With the procedure as described above it was possible to calculate a contribution to the response spectrum after each scattering collision of the primary radiation. This was done by taking the current weight of the photon and multiplying by the probability of escape, $\exp (-\Sigma y)$, and adding the product into the pulse-height interval. which included the total energy deposited up to that particular collision. In this case the energy deposited is the source energy minus the current energy of the photon minus all energy lost from the crystal by secondary radiation originating from all previous Compton events.

The additional contributions required to determine completely the response spectrum were obtained by first treating each collision of the primary radiation as a photoelectric event and then as a pair production event (if the energy was above threshold) before actually allowing the photons to scatter. In the case of a photoelectric event the energy lost from the crystal by all secondary radiation produced by the photoelectron was calculated in the same way as for a Compton ejected electron. The weight of the primary photon before the collision was then multiplied by the probability of having a photoelectric event and the product was added into the pulse-height interval corresponding to the energy deposited. The energy deposited in this case is the source energy minus the energy lost from the crystal by all secondary radiation Initiated by the photoelectron minus the energy lost from the crystal by secondary radiation from all previous Compton events. The contribution from pair production was calculated in a similar manner; however, the loss of the secondary annihilation radiation also had to be accounted for.

D. Calculation of the Peak-To-Total Ratio

For purposes of computing the peak-to-total ratio, all counts for which the energy deposition was within $5.17 \mathrm{kev}$ of the source energy was treated as occurring 
in the total absorption peak. The ratio of these counts to all counts was then taken as the peak-to-total ratio.

It should be noted that a slightly different value of the ratio would be obtained at the higher source energies if the spectrum was broadened first and then the total absorption peak peeled off from the overlapping energy-loss spectrum. This occurs because the buildup of counts near the total absorption peak caused by small bremsstrahlung losses are not easily separable from the peak and are usually included in it.

E. Broadening of the Spectrum

From the discussion of the calculation of the response spectrun, it should be noted that no account was taken of the line broadening when the spectrum was initially determined. This was compensated for in an auxiliary calculation which produced the broadened spectrm, $g(E)$, from the unbroadened spectrum, $k(E)$, by performing the integral

$$
g(E)=\int_{0}^{E_{0}} k\left(E^{\prime}\right) F\left(E, E^{\prime}\right) d E^{\prime}
$$

where $F\left(E, E^{\prime}\right)=\left(\pi \sigma^{2}\right)^{-1 / 2} \exp \left[-\frac{1}{2}\left(E-E^{1}\right)^{2} \sigma^{-2}\right]$. Here the term $\sigma$ is related to the line width at half maximum, $\Delta E$, by the relation $\Delta E=\left(8 \log _{e} 2\right)^{1 / 2} \sigma$.

A convenient expression for $\sigma$ turns out to be

$$
\sigma=\mathrm{A} \cdot \sqrt{\mathrm{E}}+\mathrm{BE}
$$

as can be seen in Fig. 2 where the experimental fractional line width, $\triangle E / E$, is given as a function of $\mathrm{E}^{-1 / 2}$ in which case 1 can easily be fit by a straight line. The solid curve in Fig. 2 is a smooth fit to the unpublished experimental data obtained at the Oak Ridge National Laboratory for a 3-in.-dia by 3-in.- 
high $\mathrm{NaI}(\mathrm{T} \ell)$ crystal. II In this case the straight line data yields values of the constants $A$ and $B$ of $0.01703(\mathrm{Mev})^{1 / 2}$ and 0.01147 respectively.

4. Comparison with Experiment

Shown in Figs. 3 through 7 are comparisons of the calculation.with various experimental results for 3-in.-dia by 3-in.-high NaI(Tl) crystals for source energies from 0.32 to $7.48 \mathrm{Mev}$. In all these figures the pulse height is given in units of $\mathrm{Mev}$ and the calculated data are normalized to a total response of one count. For comparison the experimental data were normalized to the calculated data at the total absorption peak. The constants used in Eq. I for broadening the spectrum were chosen to best fit the experimental data in each case. Each calculation is the result of 2,000 samples from the source.

Figures 3 and 4 show the experimental results of Stelson and McGowan. ${ }^{11}$ In their experiments the counter was suspended in the middle of a room by a minimum support in order to minimize background effects, and the resultant pulse-height spectrum was adjusted in an attempt to remove the remaining background contributions. The calculated data show a deeper valley just below the total absorption peak of the adjusted experimental data and tend to underestimate the same data at the smaller pulse heights. This deviation can be attributed to background effects that were not accounted for in adjusting the experimental data.

For source energies above $1 \mathrm{Mev}$ the calculated data were compared with the experimental data of Lazar and Willard ${ }^{12}$ and are shown in Figs. 5 through 7 . In these comparisons the calculation again gives an underestimate of the experimental data at small pulse-height values although there is very good agreement at the larger pulse heights. The deviation between the calculated and experimental data in these cases must also be attributed to background contributions in the experiment rather than statistical underestimates of the calculation. This is 
based on the fact that the calculation is verified at both extremes of the pulseheight spectrum: at the large pulse heights the calculation agrees with experiment and at the small pulse heights the statistical data approaches the analytic zero intercept (see Section 3B) with a fair degree of accuracy.

In the case of the $7.48 \mathrm{Mev}$ source, shown in Fig. 7, the calculated data are represented by a smooth curve in order to simplify the figure and show some additional data indicating the effect of secondary radiation on the pulse-height response spectrum. The curve labeled "no secondary losses" was calculated by letting all secondary radiation be absorbed. The curve labeled "only annihilation radiation secondary losses allowed" was calculated by letting the bremsstrahlung radiation be absorbed and tracing only the annihilation radiation. The last curve, which is labeled "all secondary losses allowed," took account of both annihilation and bremsstrahlung energy losses. As would be expected, the curve neglecting all secondary losses does not agree with experiment at all. The curve including annihilation radiation losses agrees with experiment fairly well when the experimental data are normalized to it at the total absorption peak; however, the relative heights of the two escape peaks do not agree with experiment until all secondary losses are included. It can be observed that for the case where all secondary losses are allowed the two escape peaks lie below the experimental data. This does not necessarily indicate that the calculation is incorrect, because the difference could be accounted for by the apparently large amount of background appearing in the experiment. If the calculated data were normalized to the experimental data at the first escape peak, for example, the calculated total absorption peak would be approximately $10 \%$ higher than the experimental value. 
5. Results of the Calculation

A series of calculations for a 3-in.-dia by 3-in.-high $\mathrm{NaI}(\mathrm{T} l)$ crystal were performed with a monoenergetic point source on the crystal axis $10 \mathrm{~cm}$ from one end. The source energy ranged from 0.1 to $6.0 \mathrm{Mev}$ for these cases, and for each source energy 2,000 samples of the primary source radiation were traced along with all secondary radiation as discussed in Section 3C. The intrinsic efficiency and peak-to-total ratios for these cases are presented in Fig. 8 and Table 1. The error interval indicated at the data points in Fig. 8 and in Table 1 for the peak-to-total ratio spans two standard deviations and was determined in the calculation. At energies below $1.3 \mathrm{Mev}$ the error is not indlcated in Fig. 8 because it falls within the circles marking the data points,

The response spectra from these cases are presented in Figs. 9 through 33. These spectra have been broadened using the constants $A$ and $B$ in Eq. I that were derived from Fig. 2 (see Section 3E). In all cases the curves were drawn so that the total absorption peak was located at a pulse height of 1,000 and had a height of unity. By multiplying the ordinate of each of these graphs by the normalization factor $F$, which is given in Fig. 8 and in Table 1 as a function of source energy, the response spectra will be normalized to a total response of one count.

The smooth curves shown in Figs. 9 through 33 were drawn on the assumption that the data would be of most use if presented in this form. This does not imply that these data have greater accuracy than the calculated data presented in Figs. 3 through 7. Figures 5 and 6, in fact, show typical examples of how the smooth curves were drawn through the statistical data. The over-all accuracy of the calculation can be observed by inspecting the errors indicated on the peak-to-total ratios shown in Fig. 8 and presented in Table 1. 
Table 1. Intrinsic Efficiency, Peak-to-Total Ratio, Normalization Factor, and Fractional Line Width for a 3-in.-dia by 3-in.-High NaI(Tl) Scintillation Counter. The source was an isotropic point located on the crystal axis $10 \mathrm{~cm}$ from one end.

\begin{tabular}{|c|c|c|c|c|}
\hline $\begin{array}{c}\text { Source Energy } \\
\text { (Mev) }\end{array}$ & $\begin{array}{r}\text { Intrinsic } \\
\text { Efficiency }\end{array}$ & $\begin{array}{c}\text { Peak-to-Total } \\
\text { Ratio }\end{array}$ & $\begin{array}{c}\text { Normalization } \\
\text { Constant } \\
\text { F }\end{array}$ & $\begin{array}{l}\text { Fractional } \\
\text { Line Width, } \\
\triangle \mathrm{E} / \mathrm{E} \text {, at the } \\
\text { Source Energy }\end{array}$ \\
\hline $\begin{array}{l}0.1 \\
0.15 \\
0.2 \\
0.25 \\
0.279 \\
0.3 \\
0.35 \\
0.4 \\
0.45 \\
0.5 \\
0.6 \\
0.661 \\
0.7 \\
0.8 \\
0.9 \\
1.114 \\
1.275 \\
1.38 \\
1.6 \\
1.78 \\
2.14 \\
2.4 \\
2.76 \\
3.13 \\
3.57 \\
4.0 \\
5.0 \\
6.0\end{array}$ & $\begin{array}{l}0.972 \\
0.927 \\
0.874 \\
0.825 \\
0.798 \\
0.781 . \\
0.745 \\
0.714 \\
0.688 \\
0.666 \\
0.632 \\
0.615 \\
0.605 \\
0.583 \\
0.563 \\
0.530 \\
0.510 \\
0.498 \\
0.478 \\
0.465 \\
0.445 \\
0.435 \\
0.424 \\
0.417 \\
0.411 \\
0.408 \\
0.405 \\
0.405\end{array}$ & $\begin{array}{l}0.9919 \pm 0.0004 \\
0.9779 \pm 0.0009 \\
0.9520 \pm 0.0016 \\
0.9080 \pm 0.0025 \\
0.8845 \pm 0.0030 \\
0.8546 \pm 0.0034 \\
0.8102 \pm 0.0041 \\
0.7622 \pm 0.0049 \\
0.7078 \pm 0.0054 \\
0.6683 \pm 0.0060 \\
0.6014 \pm 0.0068 \\
0.5693 \pm 0.0058 \\
0.5538 \pm 0.0073 \\
0.5036 \pm 0.0079 \\
0.4692 \pm 0.0083 \\
0.3842 \pm 0.0091 \\
0.3413 \pm 0.0095 \\
0.3262 \pm 0.0079 \\
0.3016 \pm 0.0099 \\
0.2862 \pm 0.0101 \\
0.2441 \pm 0.0102 \\
0.2143 \pm 0.0104 \\
0.1962 \pm 0.0085 \\
0.1650 \pm 0.0088 \\
0.1548 \pm 0.0107 \\
0.1345 \pm 0.0109 \\
0.1035 \pm 0.0112 \\
0.0918 \pm 0.0113\end{array}$ & $\begin{array}{l}6.06 \times 10^{-3} \\
7.04 \times 10^{-3} \\
7.67 \times 10^{-3} \\
7.96 \times 10^{-3} \\
8.08 \times 10^{-3} \\
8.02 \times 10^{-3} \\
8.03 \times 10^{-3} \\
7.92 \times 10^{-3} \\
7.66 \times 10^{-3} \\
7.50 \times 10^{-3} \\
7.17 \times 10^{-3} \\
7.00 \times 10^{-3} \\
6.95 \times 10^{-3} \\
6.60 \times 10^{-3} \\
6.36 \times 10^{-3} \\
6.13 \times 10^{-3} \\
5.74 \times 10^{-3} \\
5.60 \times 10^{-3} \\
5.36 \times 10^{-3} \\
5.05 \times 10^{-3} \\
4.76 \times 10^{-3} \\
4.40 \times 10^{-3} \\
4.06 \times 10^{-3} \\
3.64 \times 10^{-3} \\
3.40 \times 10^{-3} \\
3.01 \times 10^{-3} \\
2.49 \times 10^{-3} \\
2.29 \times 10^{-3}\end{array}$ & $\begin{array}{l}0.1538 \\
0.1306 \\
0.1167 \\
0.1072 \\
0.1029 \\
0.1002 \\
0.0948 \\
0.0904 \\
0.0868 \\
0.0837 \\
0.0788 \\
0.0764 \\
0.0749 \\
0.0718 \\
0.0693 \\
0.0650 \\
0.0625 \\
0.06115 \\
0.0587 \\
0.0571 \\
0.0544 \\
0.0529 \\
0.0511 \\
0.0497 \\
0.0482 \\
0.0471 \\
0.0450 \\
0.0434\end{array}$ \\
\hline
\end{tabular}


The change in the spectrum as the source energy changes is obvious from Figs. 9 through 33. One feature of the spectrum is worth a brief discussion, however, and that is the slight hump that appears between the two escape peaks for a 1.6-Mev source energy as seen in Fig. 24. This hump is apparently caused by the annihilation radiation where one of the photons escapes and the other escapes after one scattering. It is essentially the appearance of the Compton peak for annihilation radiation. It is prominent at $1.6 \mathrm{Mev}$ because the escape peaks have not built up sufficiently to mask the hump when they are broadened. This effect can also be observed in Fig. 5 which shows the response of a crystal to a $1.78-\mathrm{Mev}$ source.

\section{Acknowledgements}

The authors are indebted to $\mathrm{P} . \mathrm{R}$. Bell who originally suggested this problem and to R. W. Peelle and G. T. Chapman for many helpful discussions. We wish to thank P. H. Stelson and F. K. McGowan for granting us the use of unpublished experimental data. 
References

1. R. I. Heath, "Scintillation Spectrometry Gamma-Ray Spectrum Catalogue," AEC Research and Development Report IDO-16408 (1957).

2. M. J. Berger and J. Doggett, J. Research Natl. Bur. Standards $\underline{66}$ (19.56) 355.

3. C. M. Davisson and L. A. Beach, "A Study of Photons in Sodium Iodide Scintillation Crystals," U.S. Naval Research Laboratory Report NRL-5408 (1959).

4. W. F. Miller and W. J. Snow, Rev. Sci. Instr. 31 (1960) 39.

5. C. D. Zerby and H. S. Moran, "IBM-704 Codes for Predicting the Response of Garma-Ray Scintillation Counters," Oak Ridge National Laboratory Report CF $-60-5-72(1960)$.

6. C. D. Zerby, A. Meyer, and R. B. Murray, Nucl. Instr., to be published.

7. G. W. Grodstein, "X-Ray Attenuation Coefficients from $10 \mathrm{kev}$ to $100 \mathrm{Mev}$," Nat1. Bur. Standards Report NBS-583 (1957):

8. Electrons with energies of $1.0,4.0$, and $6.0 \mathrm{Mev}$ have residual path lengths of $0.2,0.9$, and $1.3 \mathrm{~cm}$, respectively in $\mathrm{NaI}(\mathrm{Tl})$.

9. C. D. Zerby and H. S. Moran, "Bremsstrahlung Spectra in NaI and Air," Oak Ridge National Laboratory Report, ORNL-2454 (1958).

10. W. Heitler, The Quantum Theory of Radiation, (Oxford University Press, London, 1954), 3rd Ed., p. 385.

11. Unpublished data of P. H. Stelson and F. K. McGowan, Oak Ridge National Laboratory.

12. N. H. Lazar and H. B. Willard, Oak Ridge National Laboratory Report ORNL$2076(1956)$, p. 55 


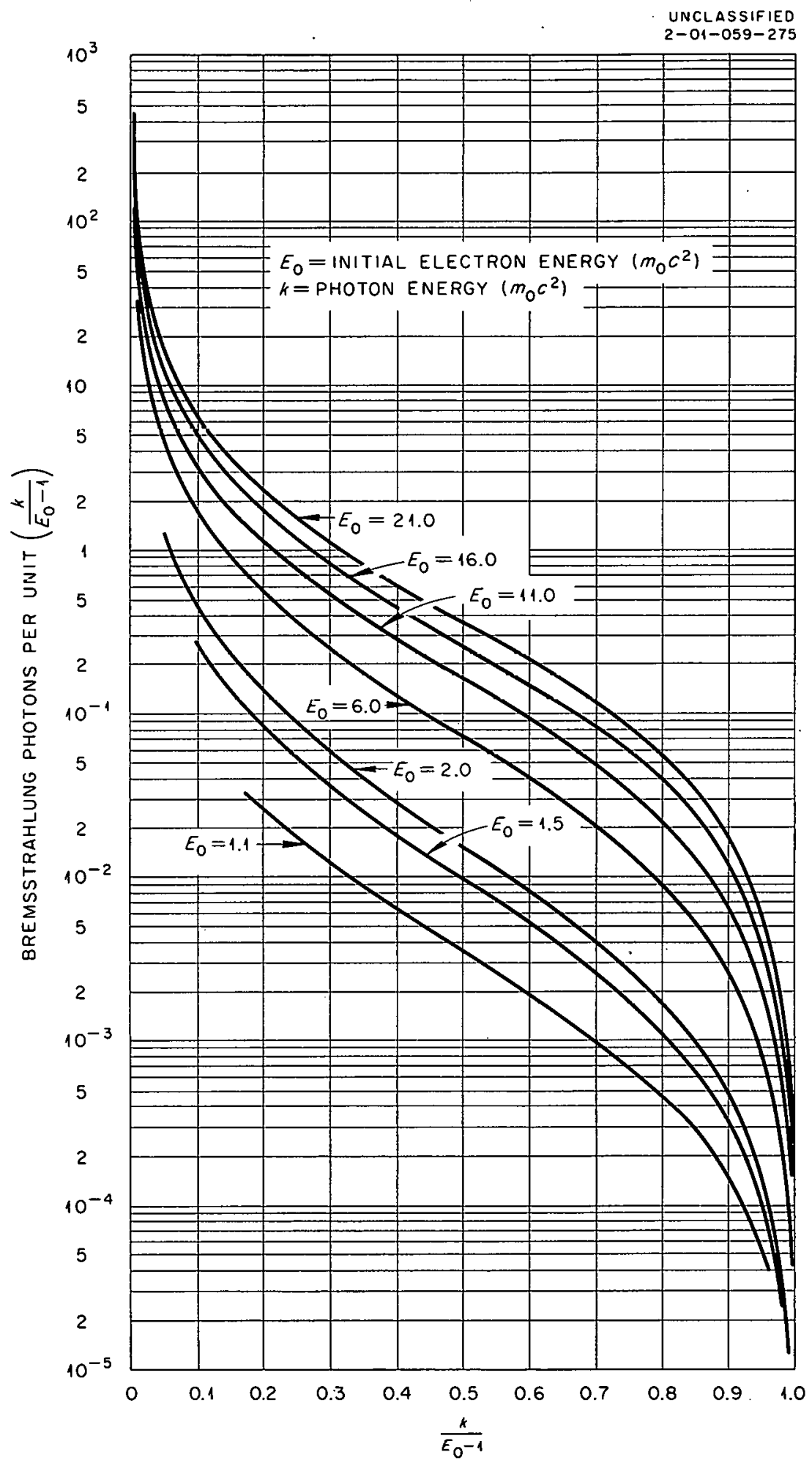

Fig. 1. Bremsstrahlung Spectra from an Electron Slowing Down in an Infinite Sodium Iodide Crystal. The curves are labeled with the initial total energy (kinetic plus rest mass energy) of the electron in rest mass units. 


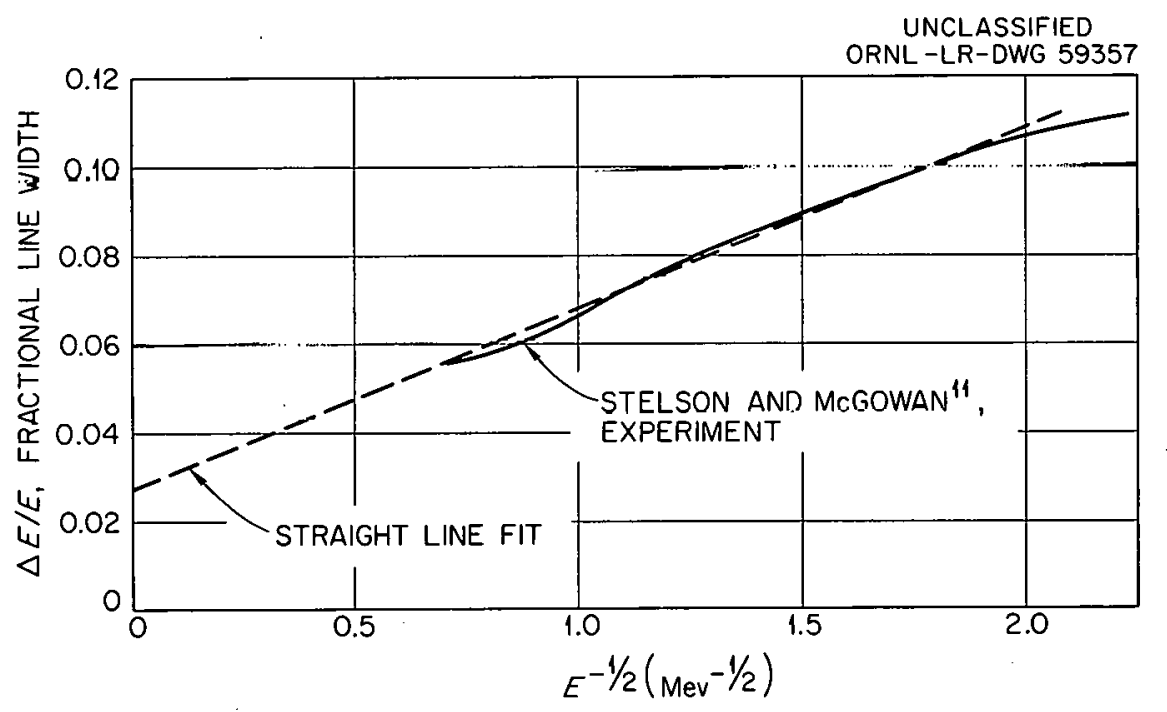

Fig. 2. Fractional Line Wiath, $\Delta E / E$, for a 37 in.-dia by 3-in.-High $\mathrm{NaI}(\mathrm{T} \ell)$ Crystal as a Function of $\mathrm{E}^{-1 / 2}$. Here $\mathrm{E}$ is the energy absorbed by the crystal in units of $\mathrm{Mev}$ and $\Delta \mathrm{E}$ is the line. width at half maximum. 


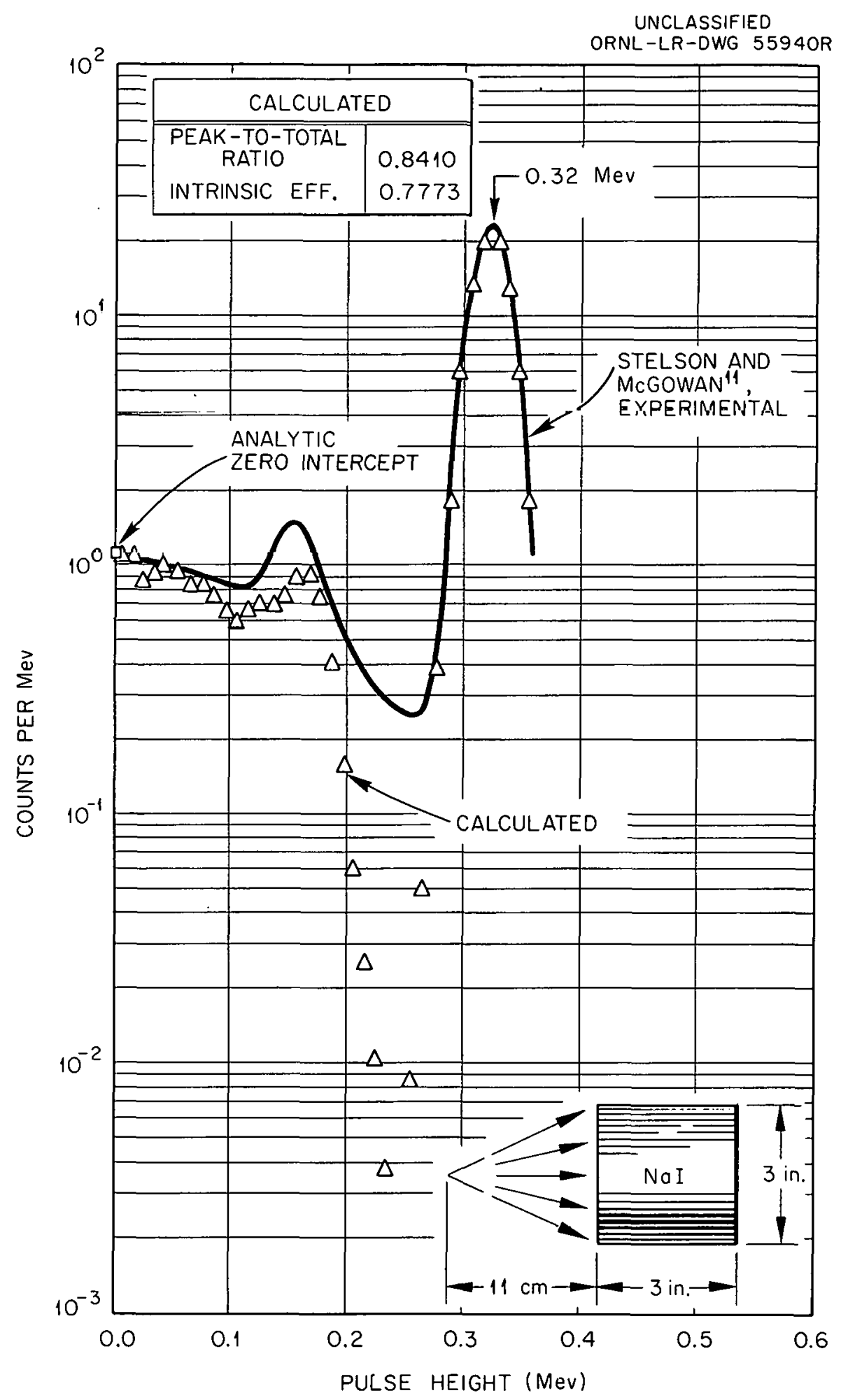

Fig. 3. Calculated and Experimental Response Spectrum from a 3-in.-dia by 3-in.-High NaI(Tl) Scintillation Counter for $0.32-\mathrm{MeV}$ Incident Gamma Rays. The isotropic point source was located $11 \mathrm{~cm}$ from the end of the crystal. 


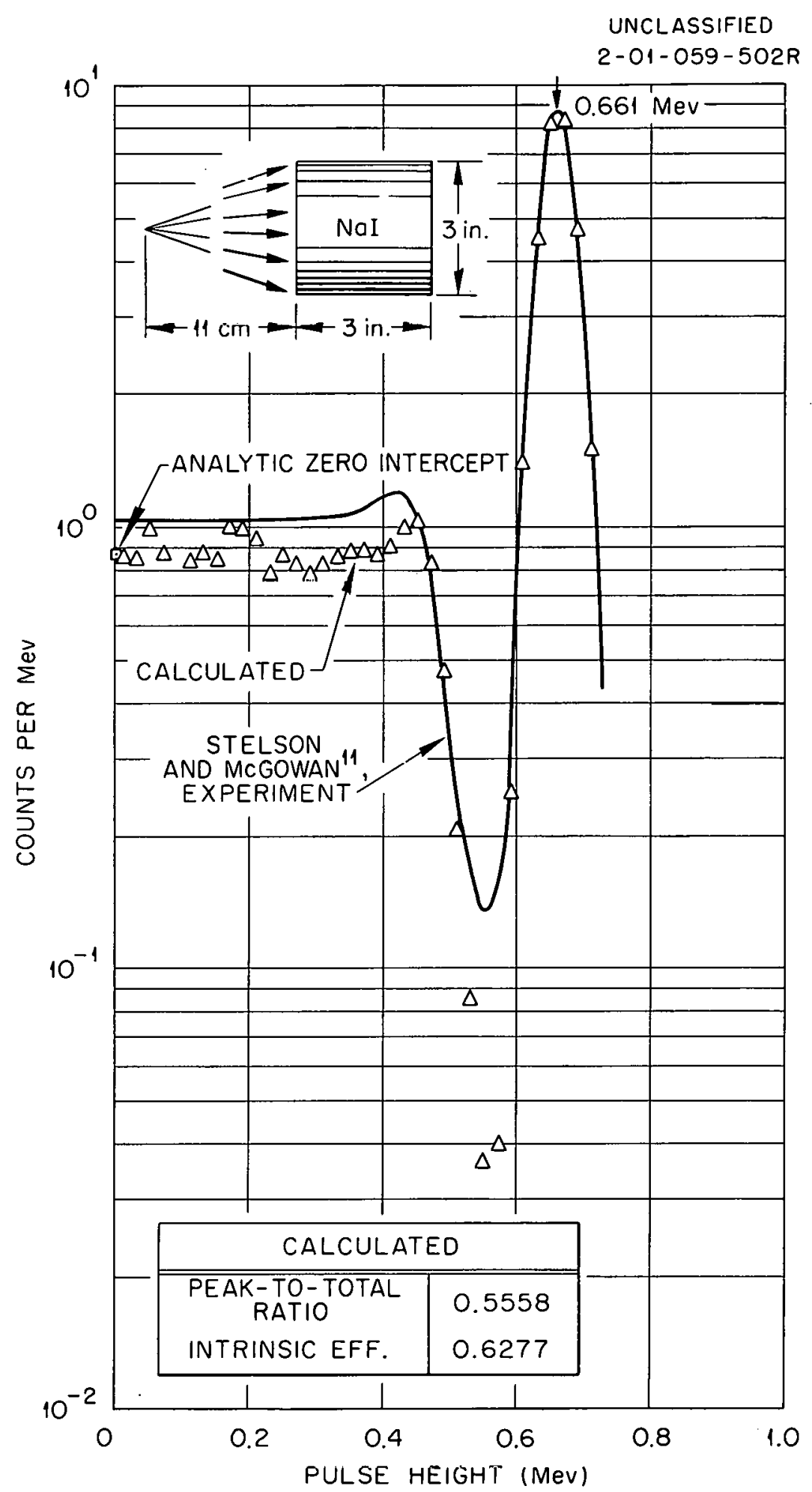

Fig. 4. Calculated and Experimental Response Spectrum from a 3-in,-dia by 3-in.-High $\mathrm{NaI}(\mathrm{Tl})$ Scintillation Counter for $0.661-\mathrm{Mev}$ Incident Gamma Rays. The isotropic point source was located $11 \mathrm{~cm}$ from the end of the crystal. 


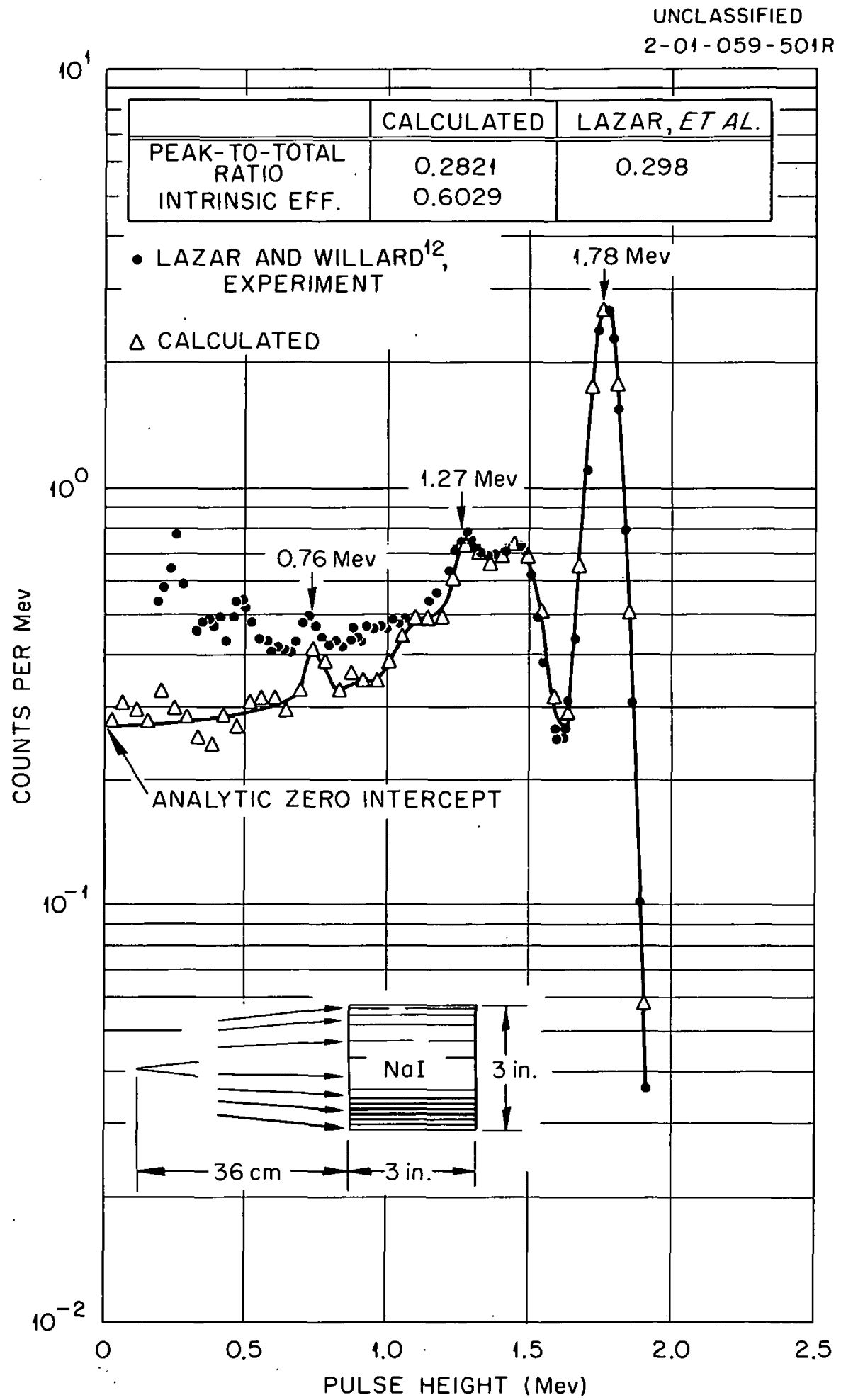

Fig. 5. Calculated and Experimental Response Spectrum from a 3-in.-dia by 3-in. -High $\mathrm{NaI}(\mathrm{Tl})$ Scintillation Counter for 1.78-Mev Incident Gamma Rays. The isotropic point source was located $36 \mathrm{~cm}$ from the end of the crystal. 


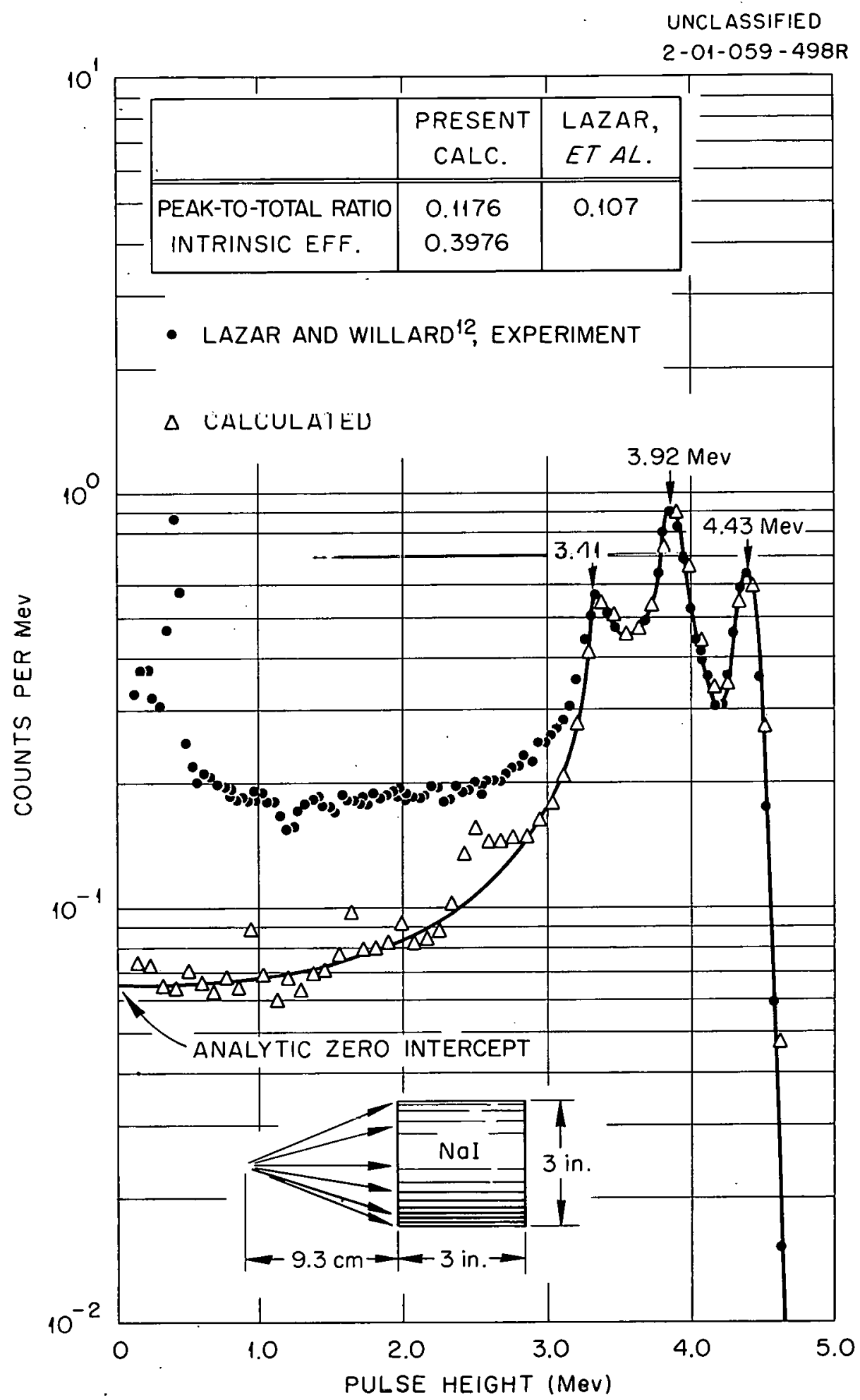

Fig. 6. Calculated and Experimental Response Spectrum from a 3-in.-dia by 3-in.-High NaI(Tl) Scintillation Counter for 4.43-Mev Incident Gamma Rays. The isotropic point source was located $9.3 \mathrm{~cm}$ from the end of the crystal. 


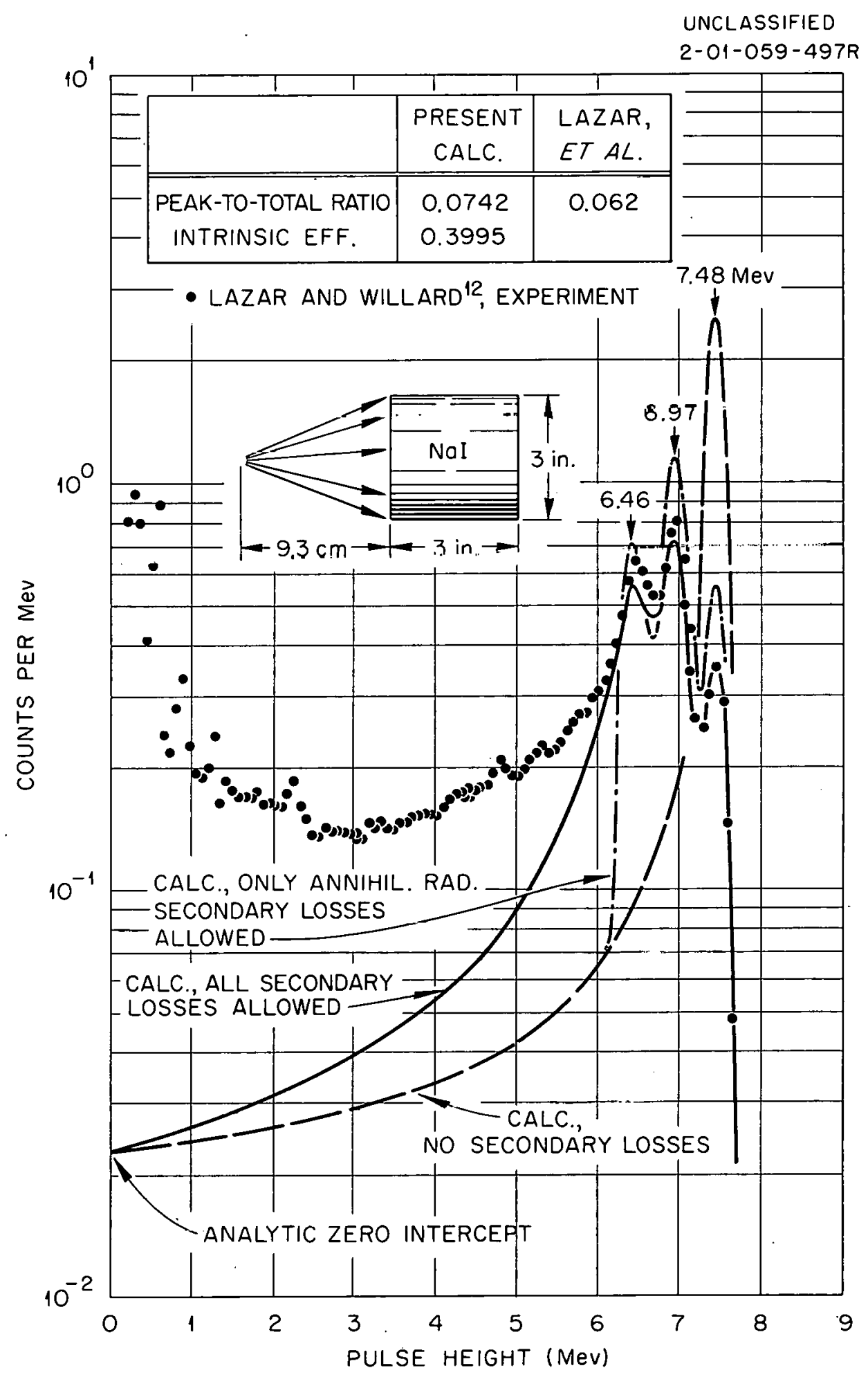

Fig. 7. Calculated and Experimental Response Spectrum from a 3-in.-dia by 3-in.-High $\mathrm{NaI}(\mathrm{T} \ell)$ Scintillation Counter for $7.48 \mathrm{-Mev}$ Incident Gamma Rays. The isotropic point source was located $9.3 \mathrm{~cm}$ from the end of the crystal. 


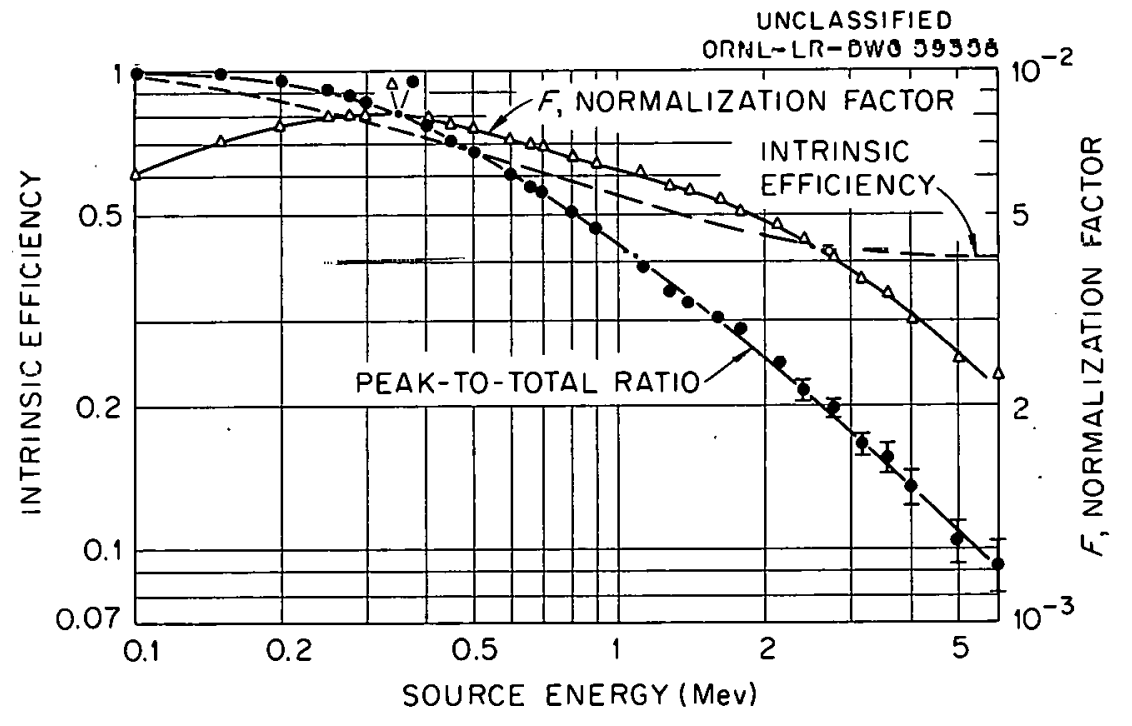

Fig. 8. Calculated Values of the Peak-to-Total Ratio, Intrinsic Efficiency, and the Normalization Factor, Which Is Described in the Text, as a Function of Source Energy for a 3-in.-dia by 3-in.-High NaI(Tl) Scintillation Counter. The source was an isotropic point located $10 \mathrm{~cm}$ from the end of the crystal. 


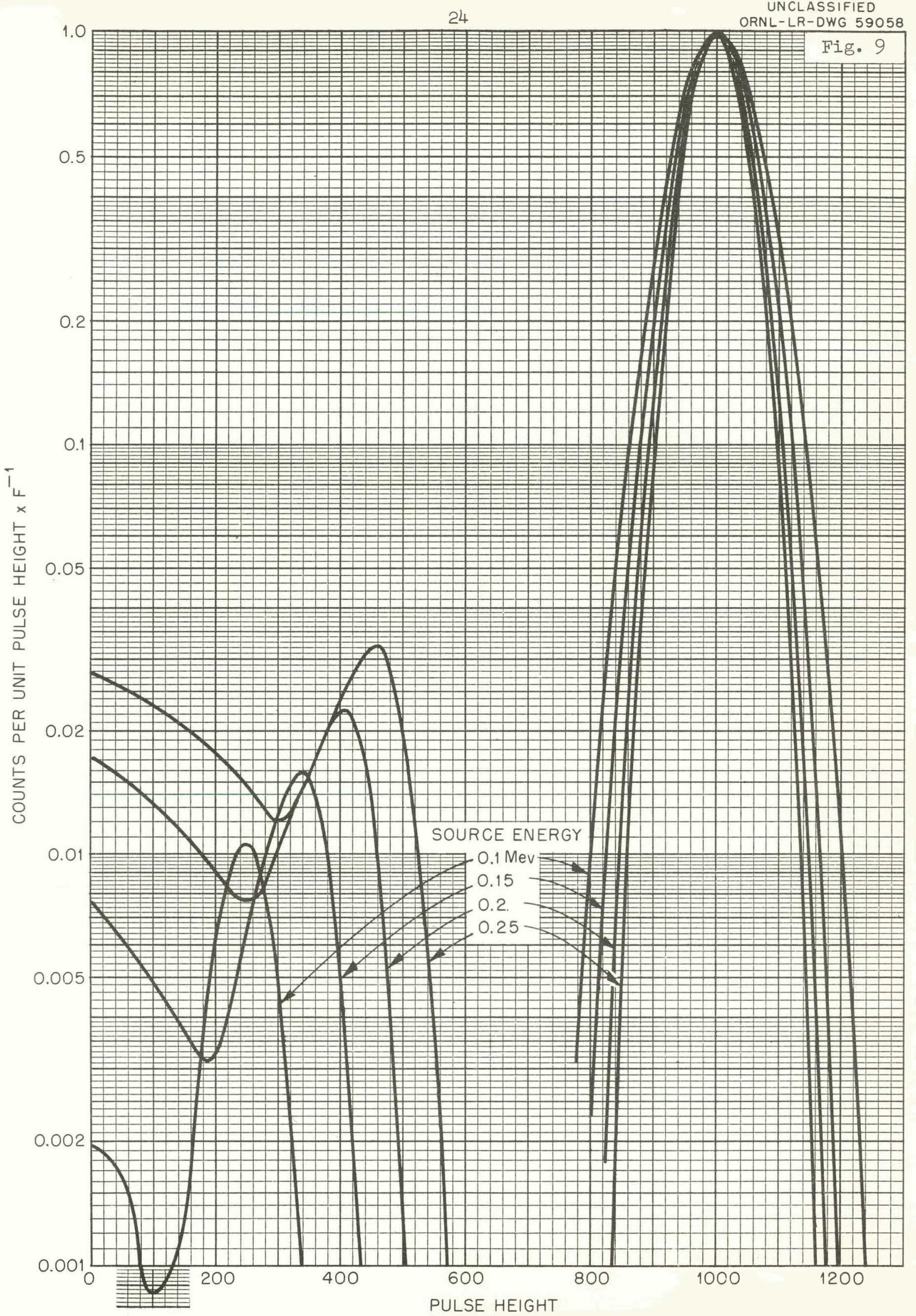




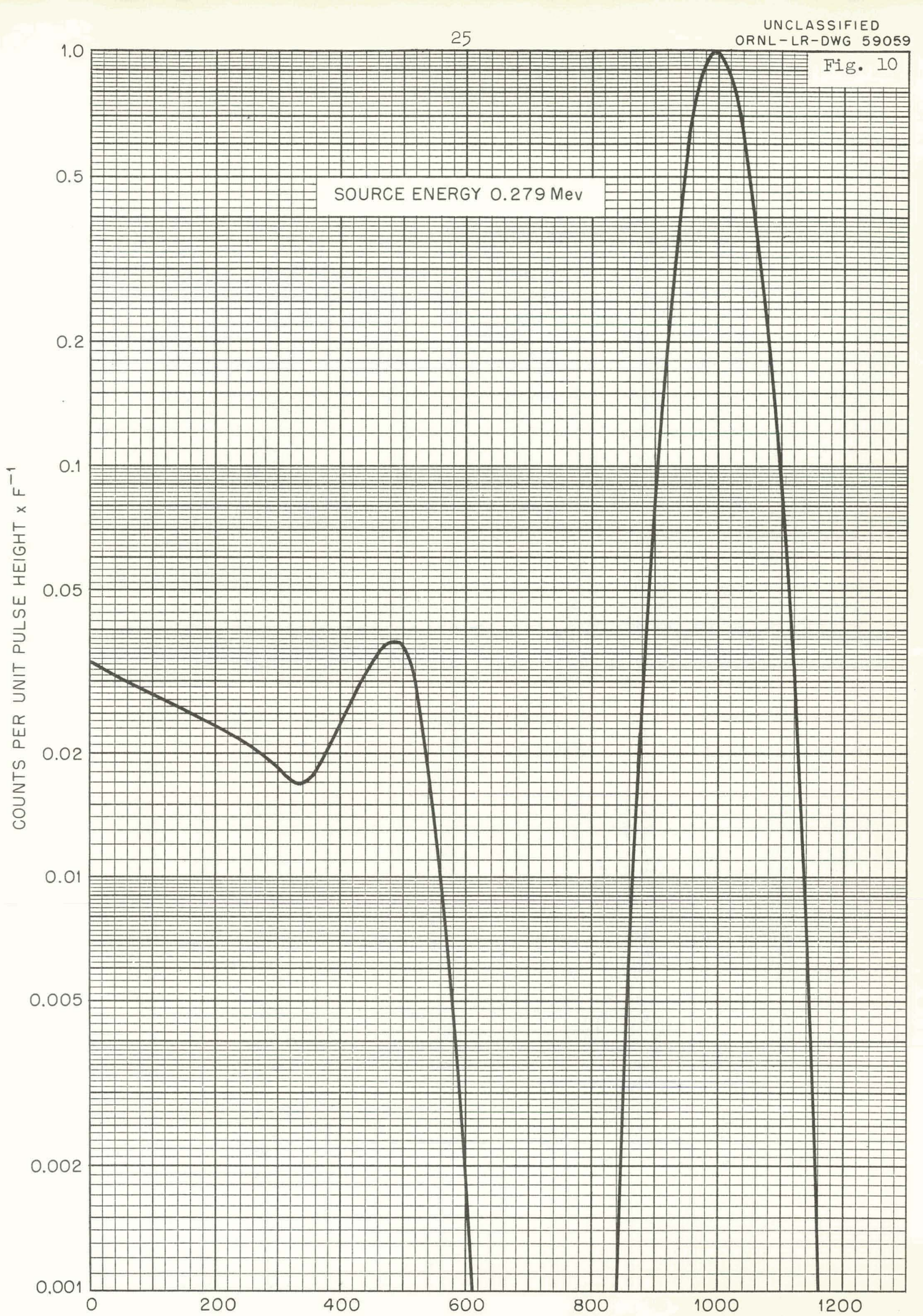




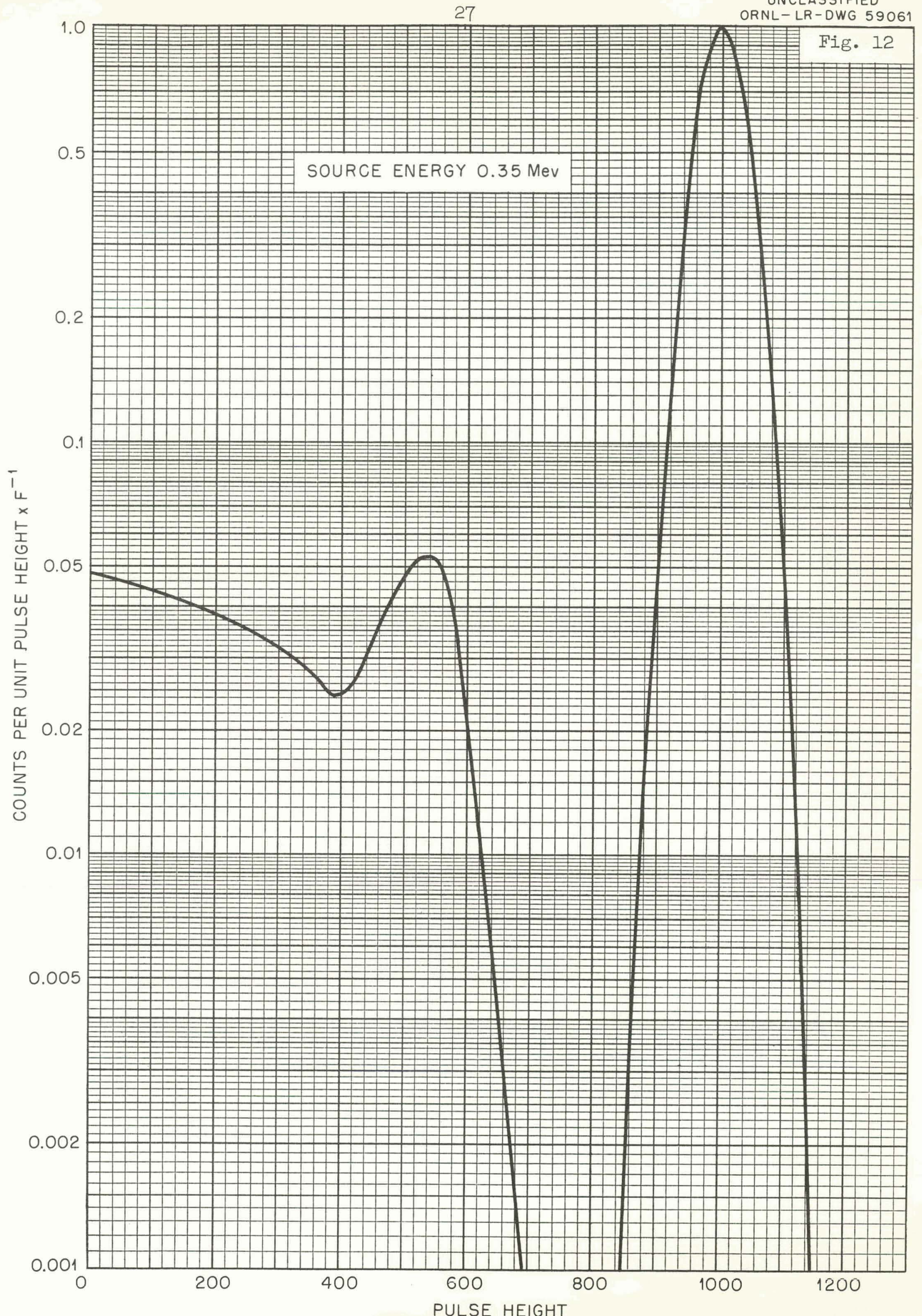




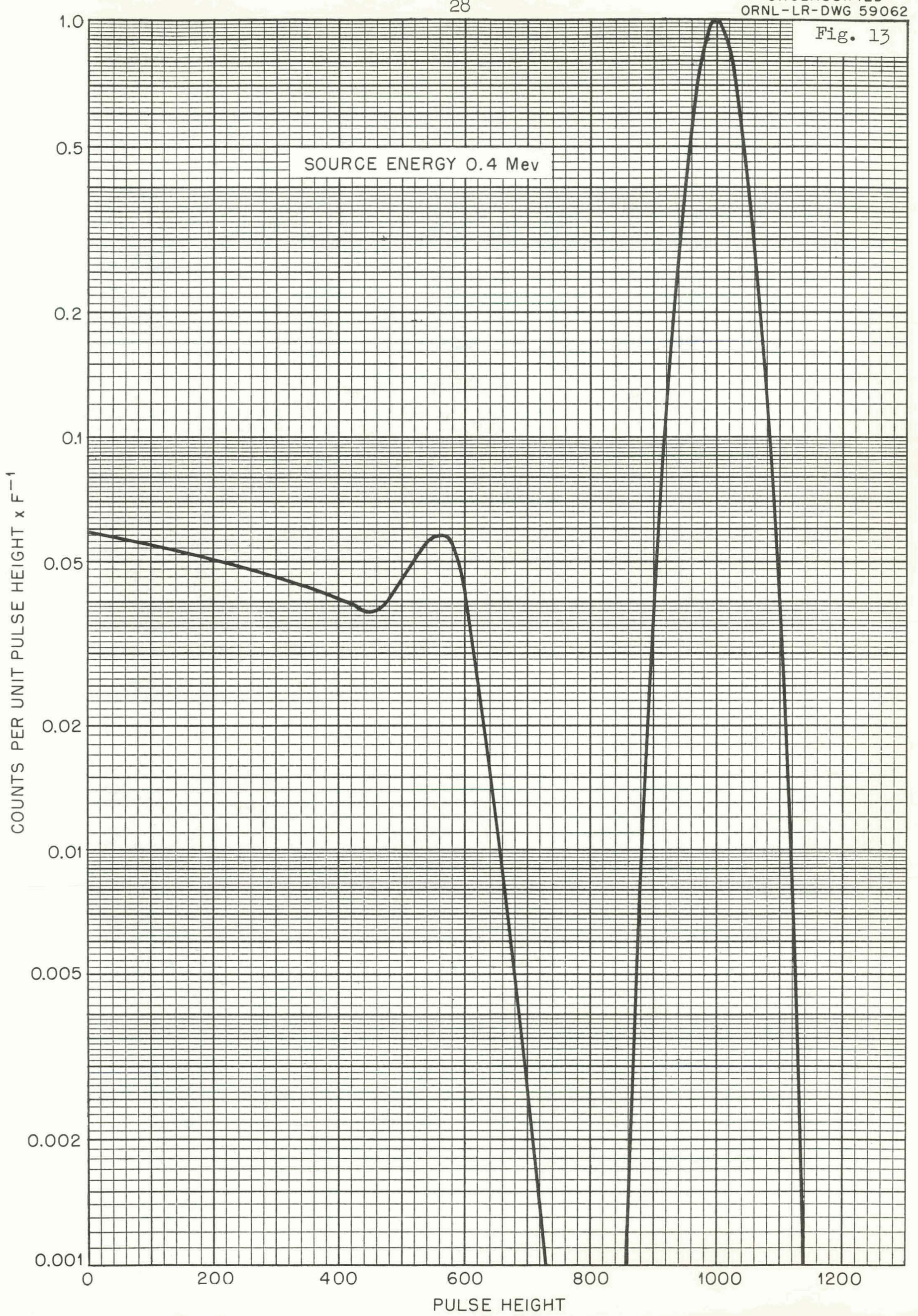




\section{UNCLASSIFIED}

ORNL-LR-DWG 59063

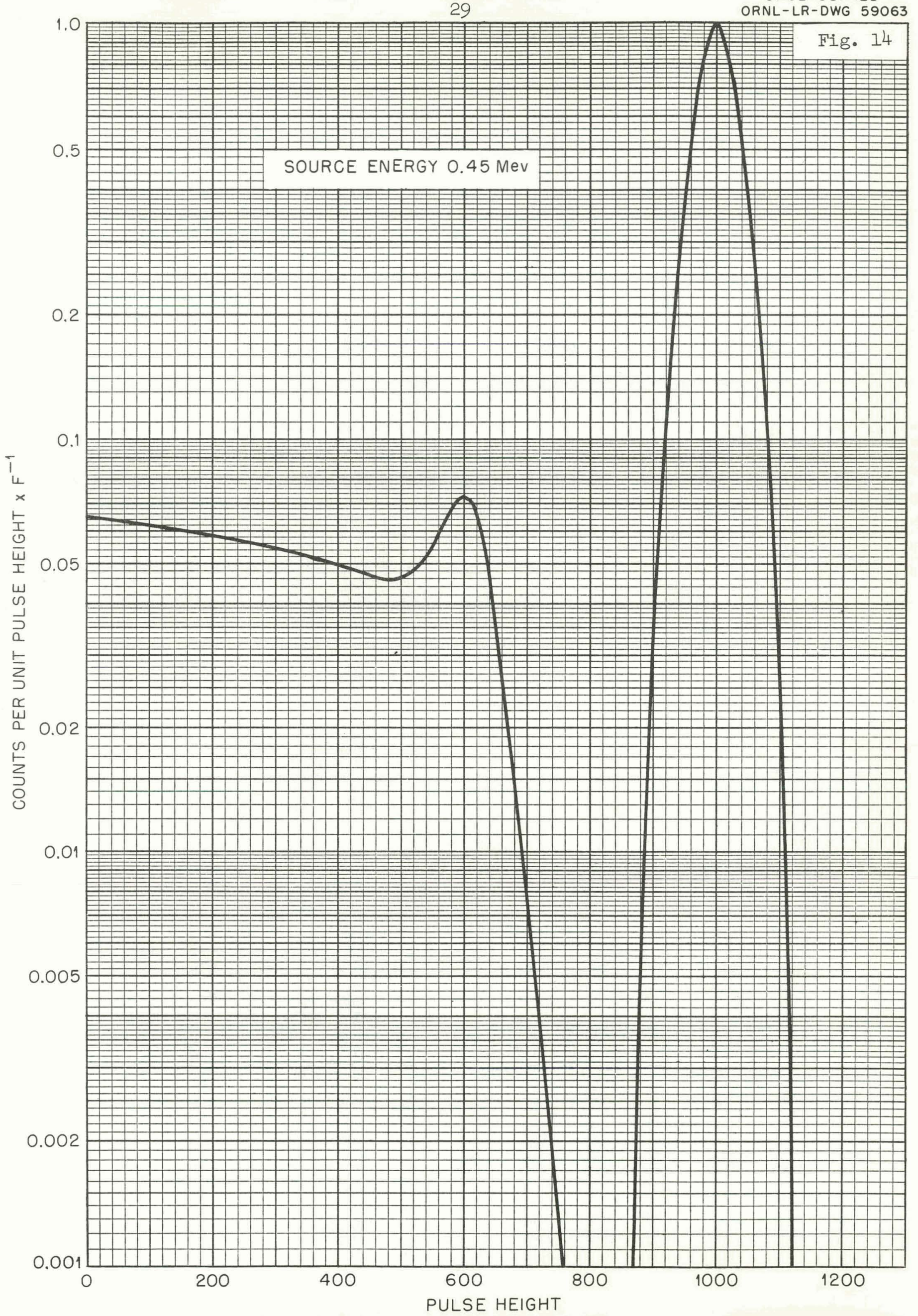


UNCLASSIFIED

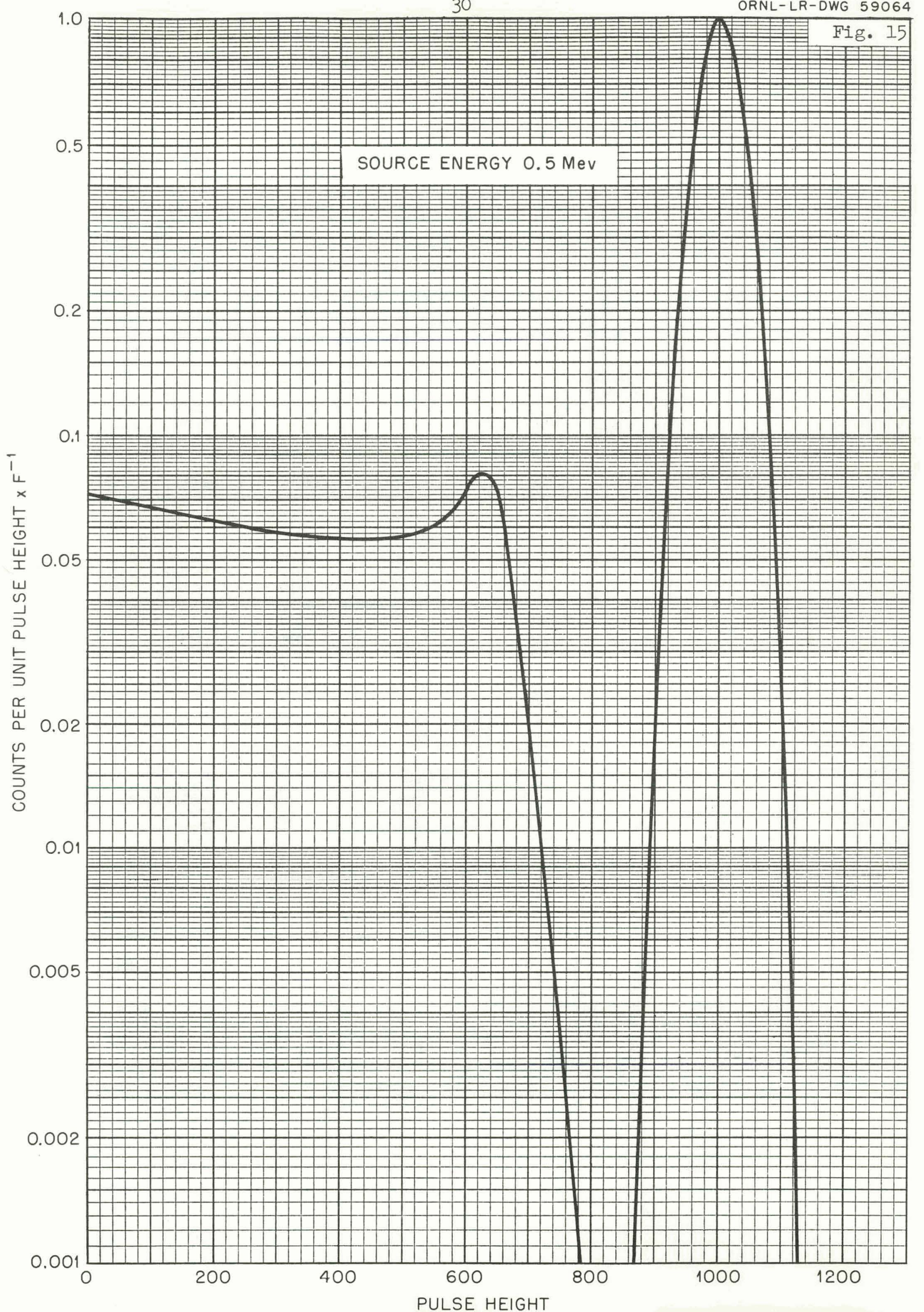




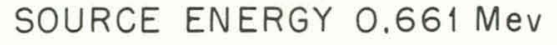

0.5

0.2
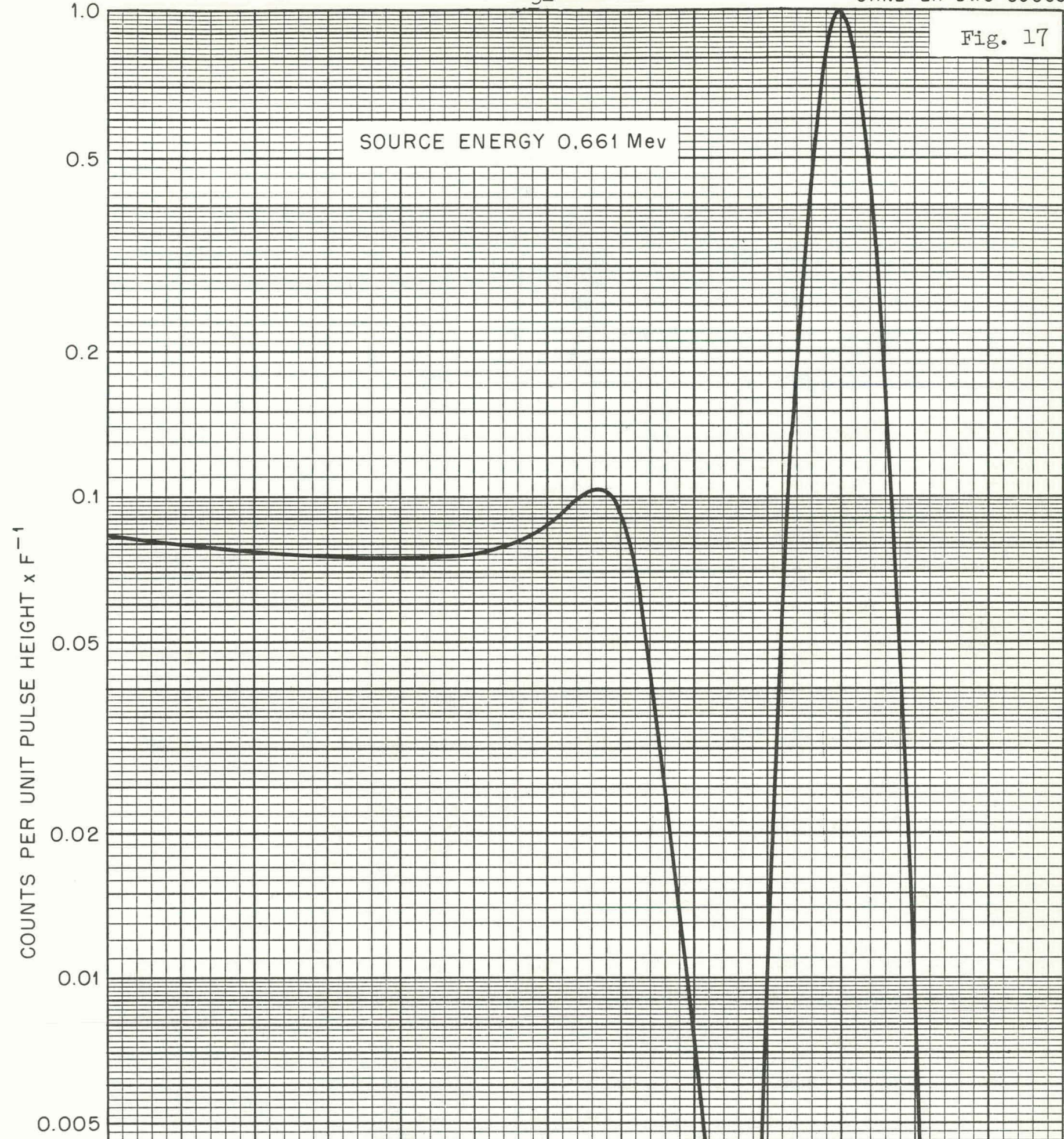

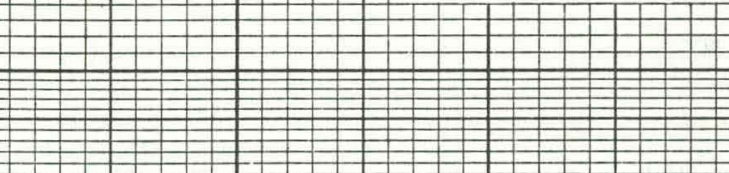

E

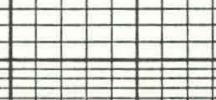

$+$

-

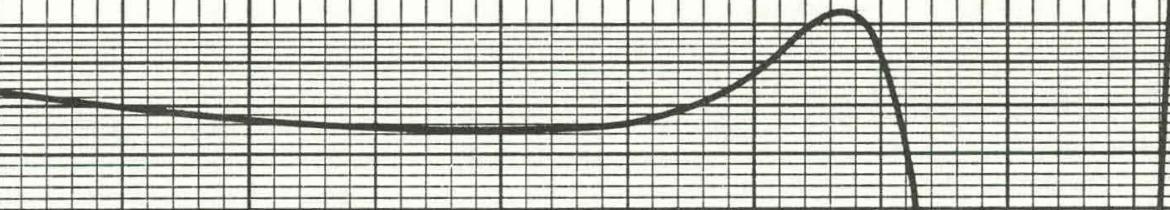




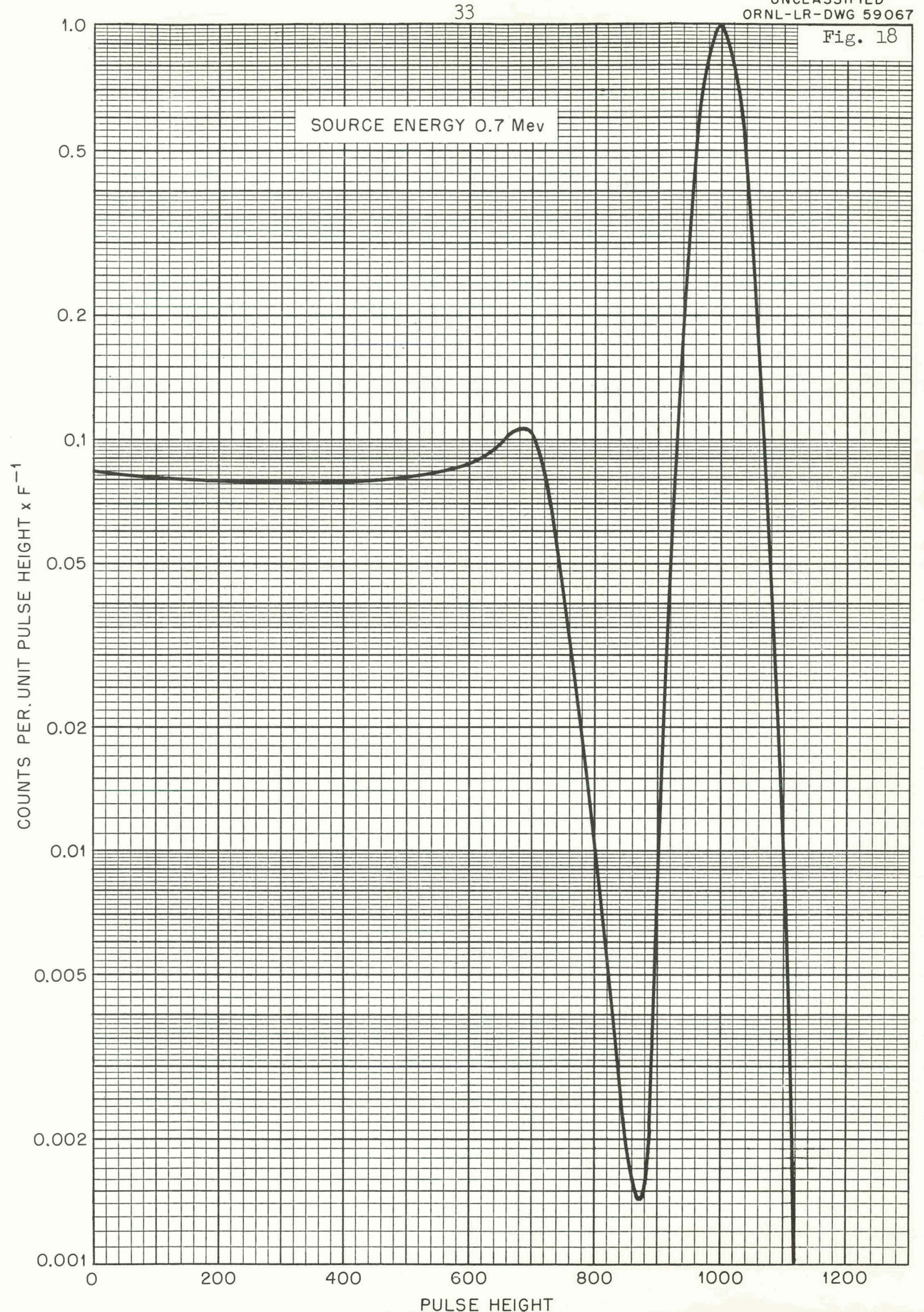


UNCLASSIFIED

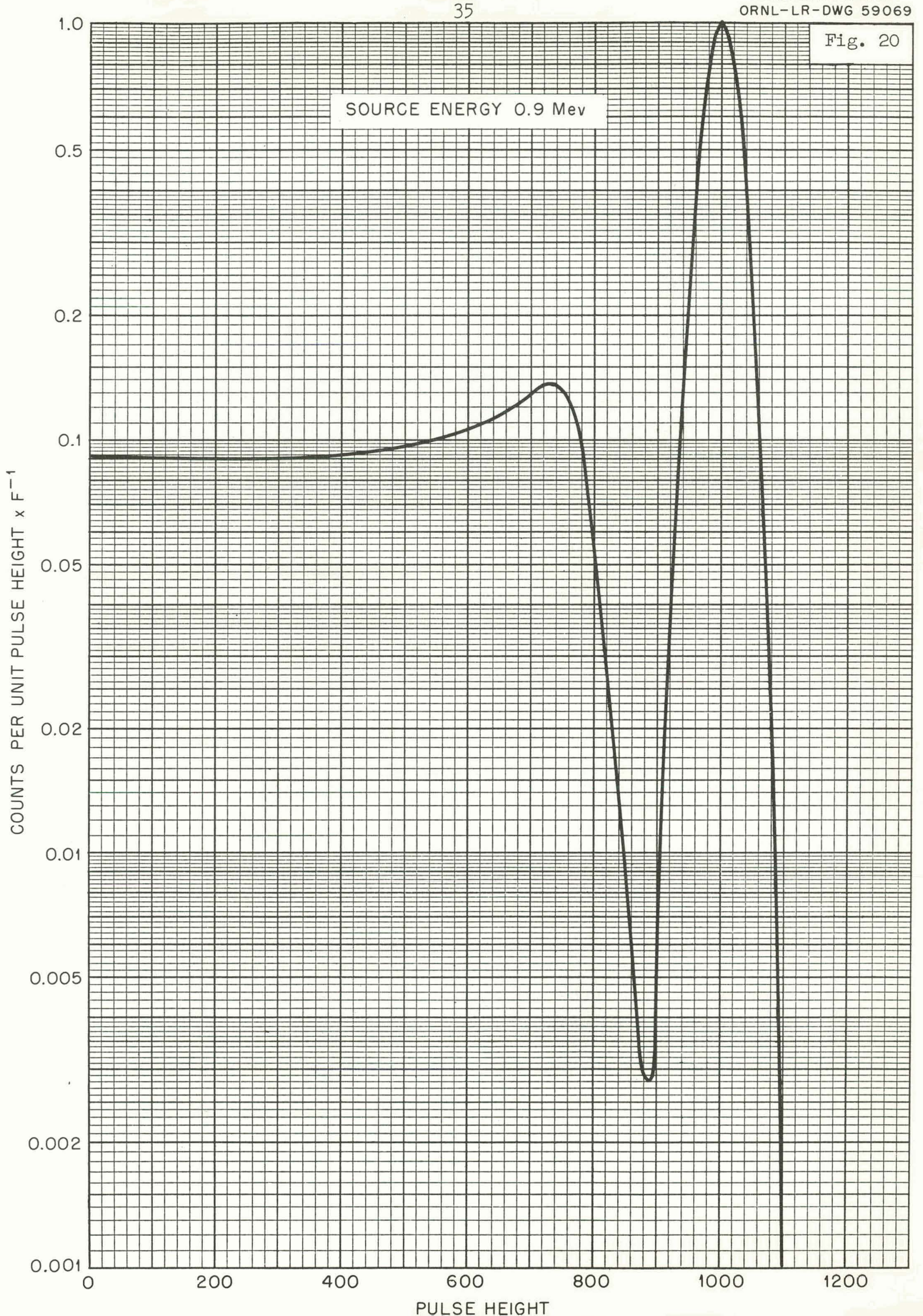




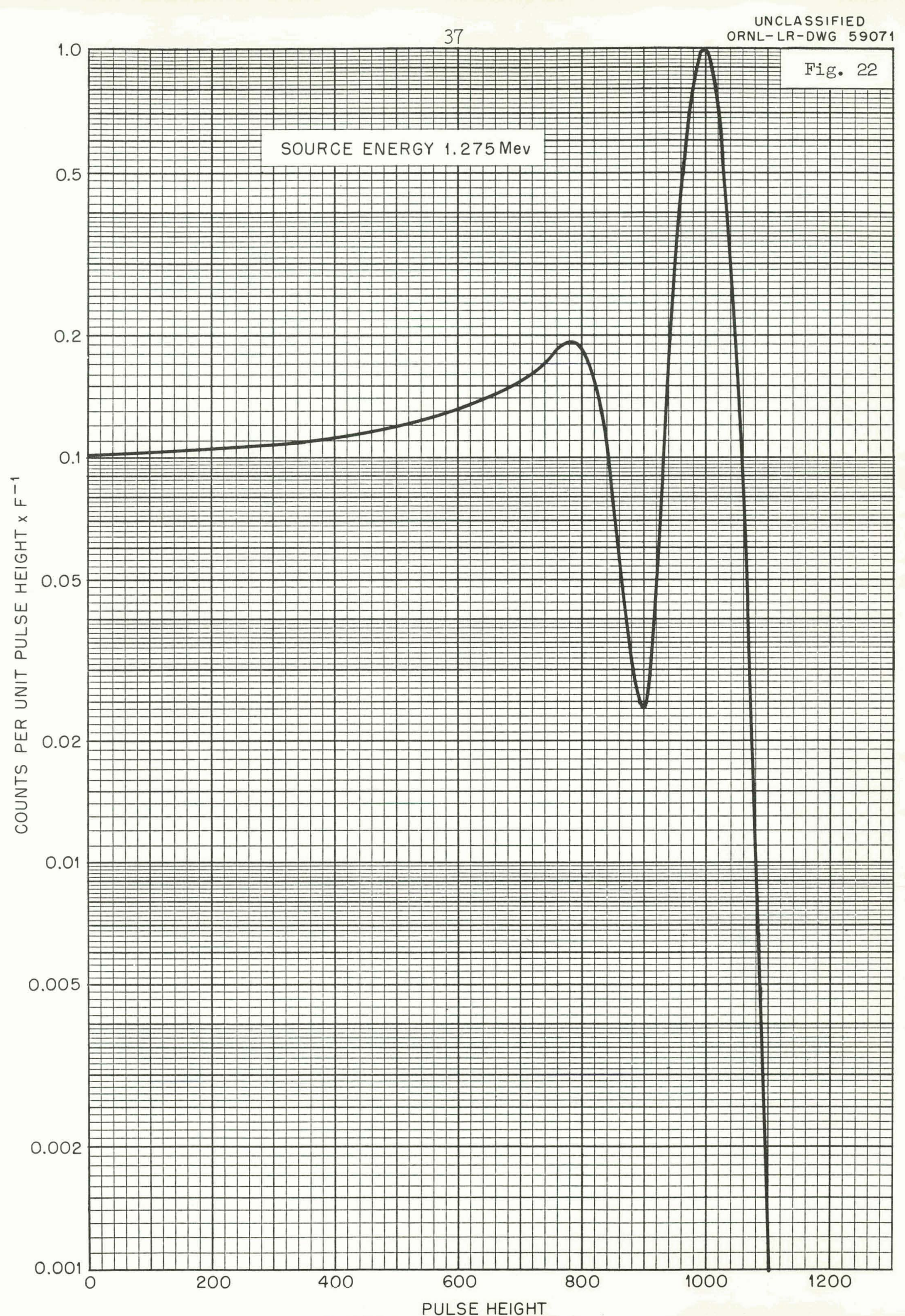




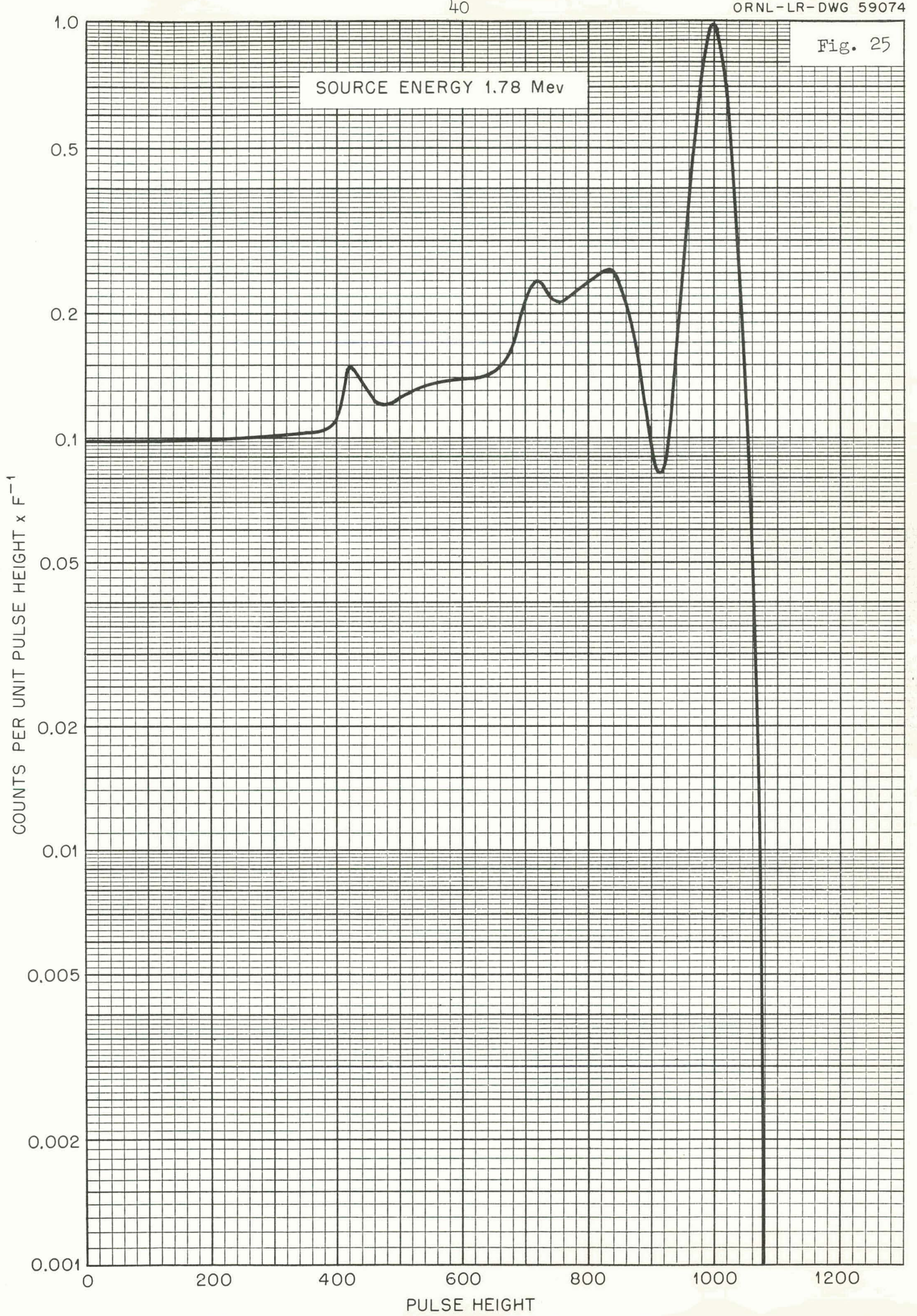




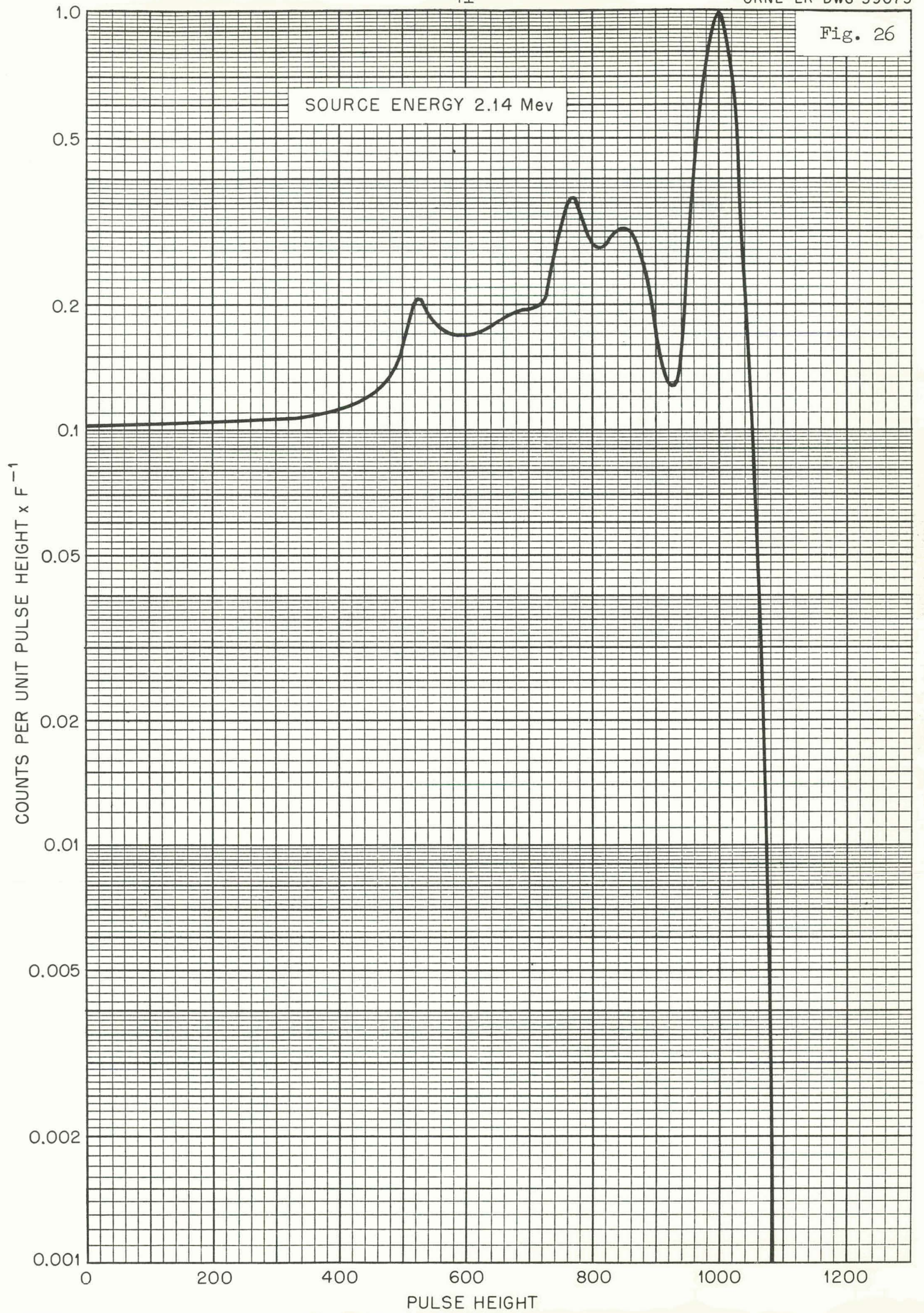




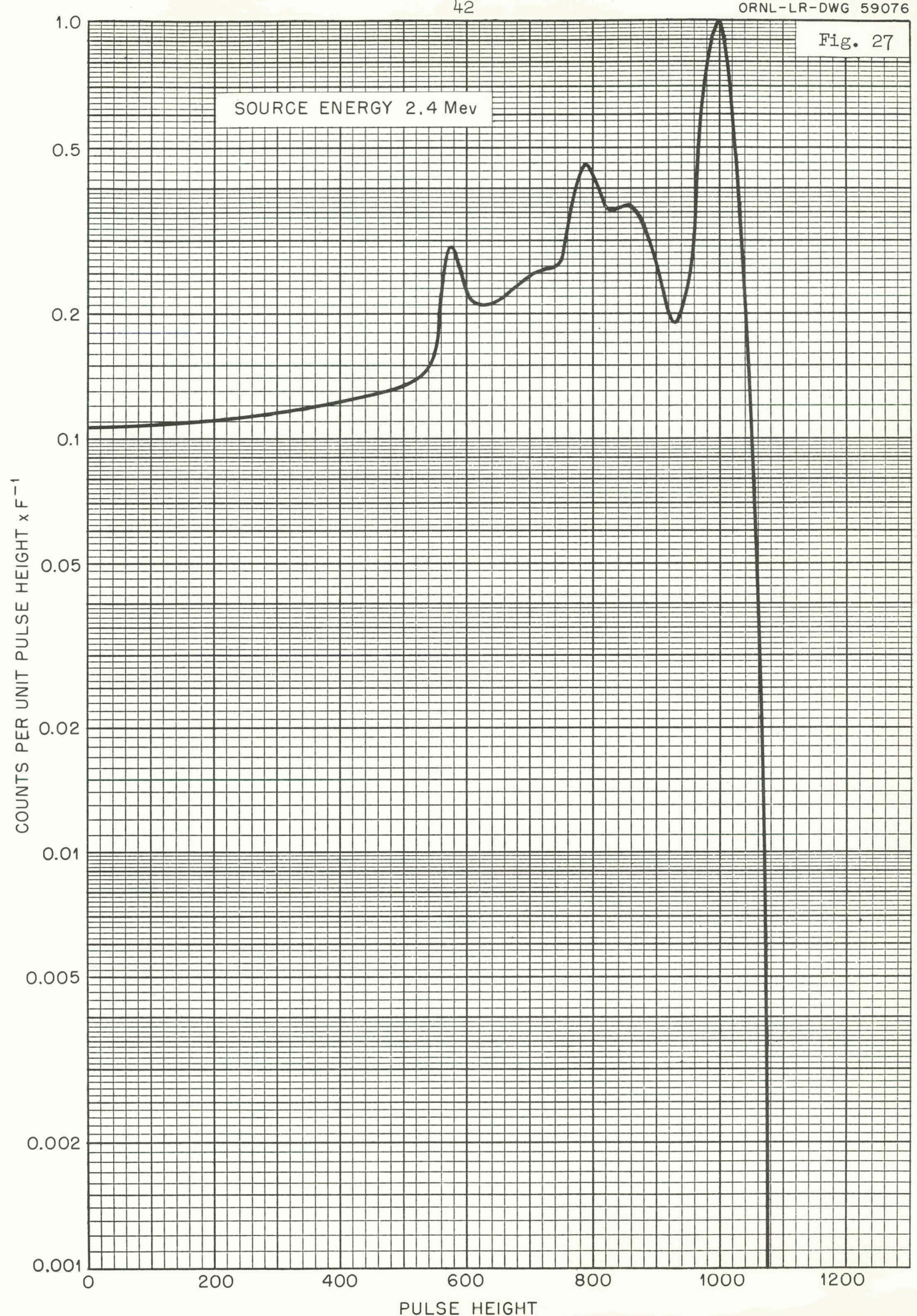




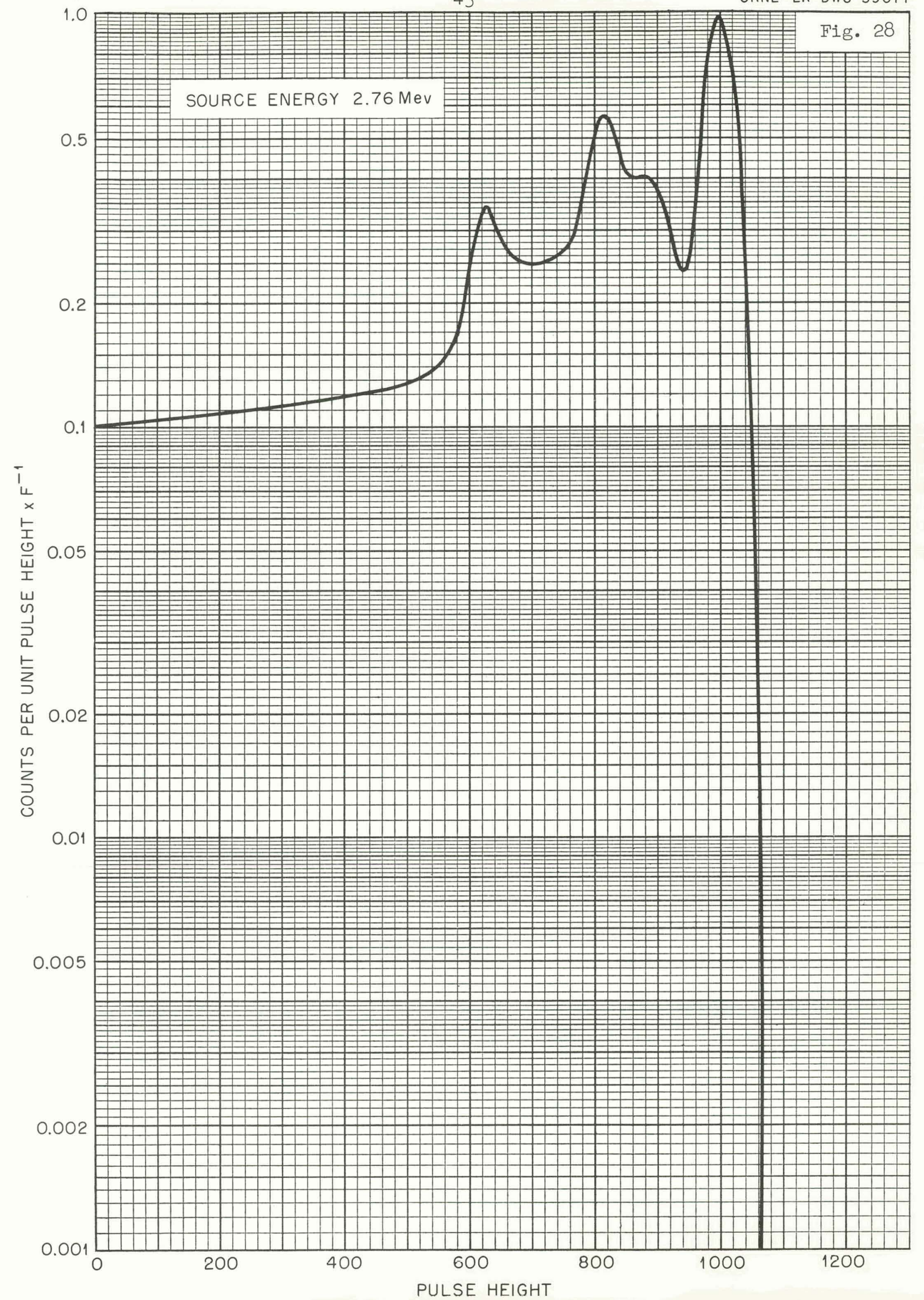


UNCLASSIFIED

1.0 W $1+$ ORNL-LR-DWG 59079 SOURCE ENERGY $3.57 \mathrm{MeV}$

0.5 \begin{tabular}{|l|l|l|l|l|l|l|l|}
\hline & & & & & & & \\
\hline
\end{tabular}

0.2

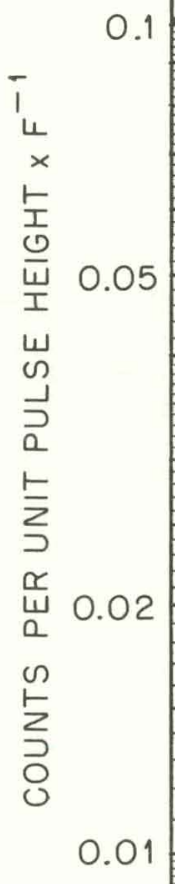

0.005 $-$
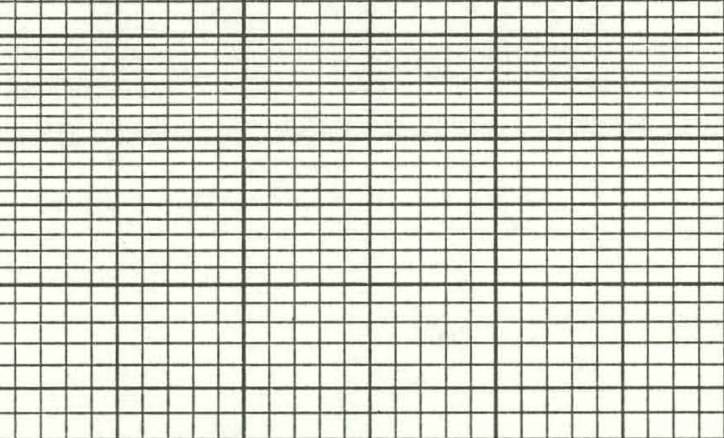

\section{(1)}

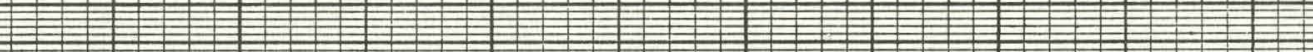
\begin{tabular}{lllll}
2 & \\
\hline
\end{tabular} \begin{tabular}{llllllll}
\hline & \\
\hline
\end{tabular}

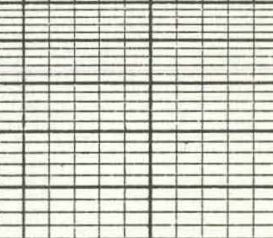

\subsection{2}

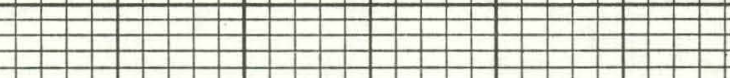

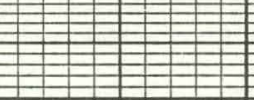
- 1 


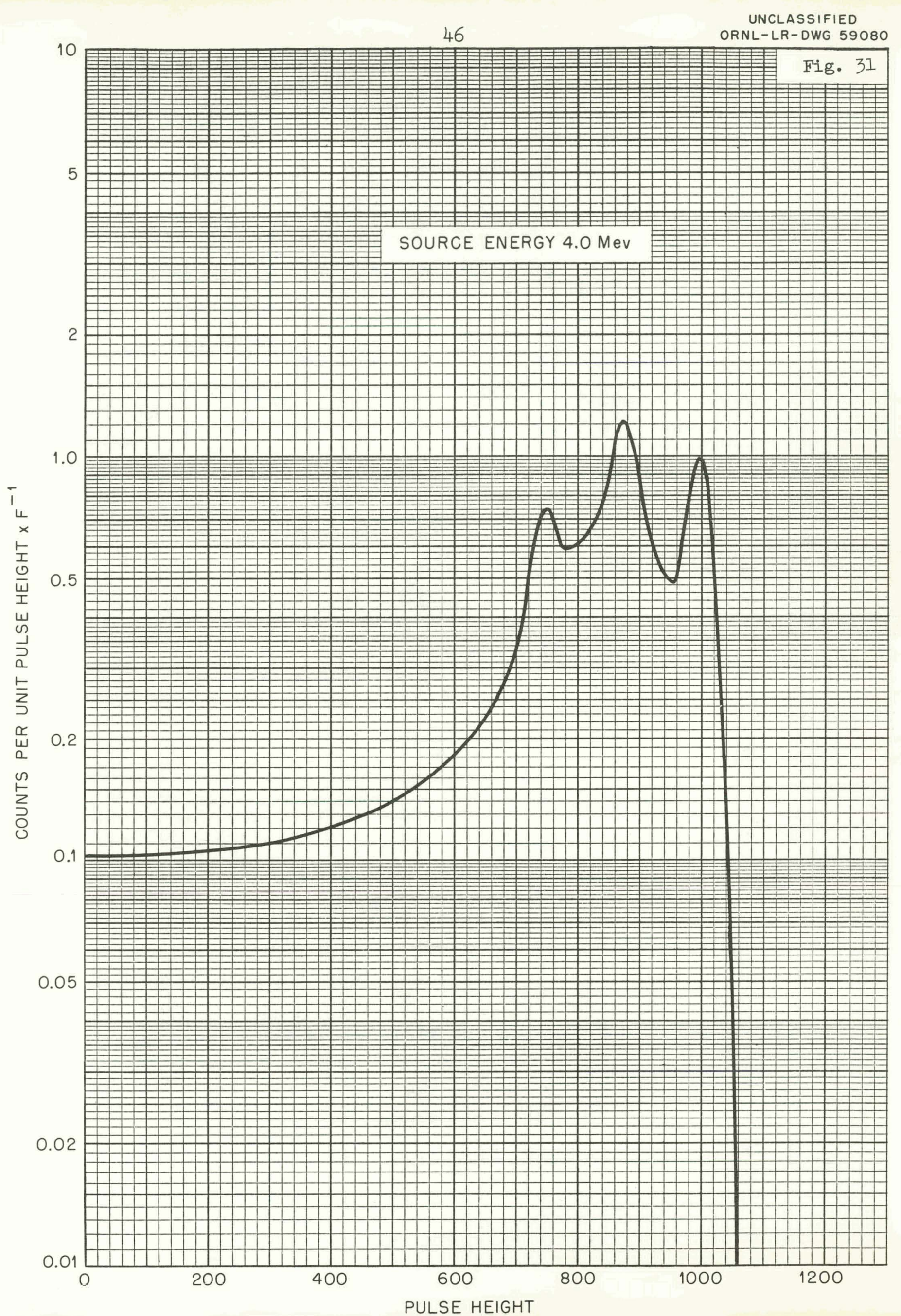


H SOURCE ENERGY $5.0 \mathrm{Mev}$

2

-
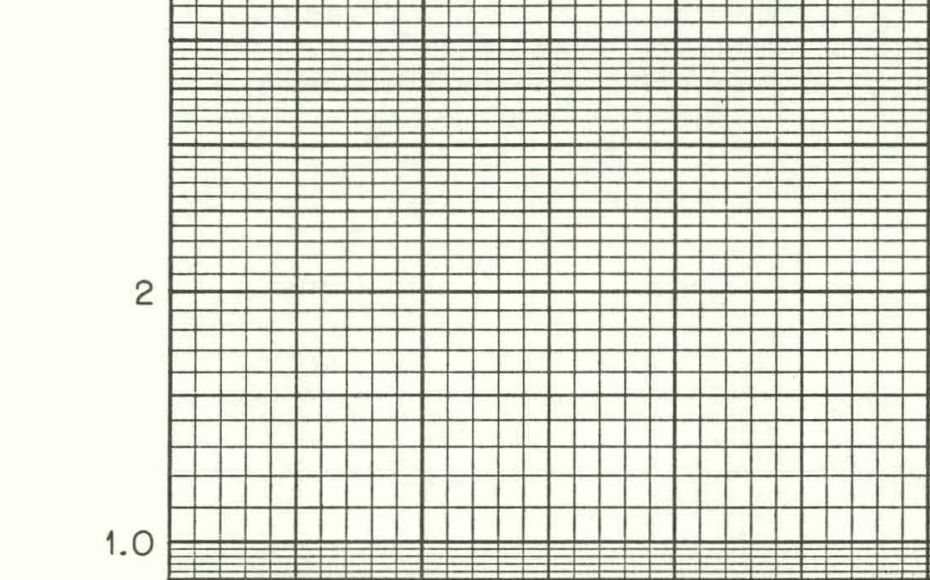

1.0
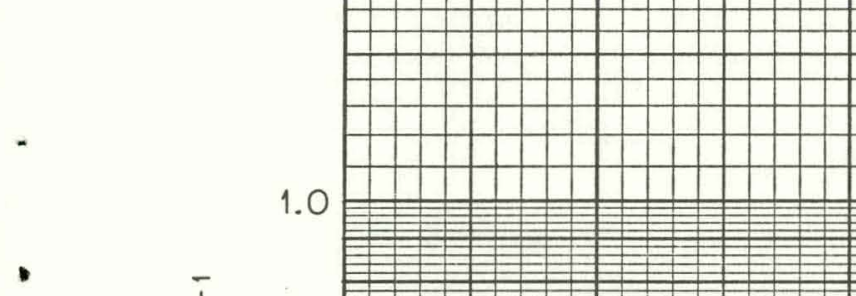

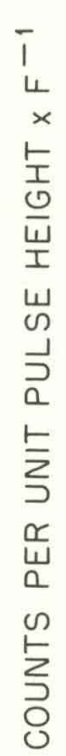

0 .
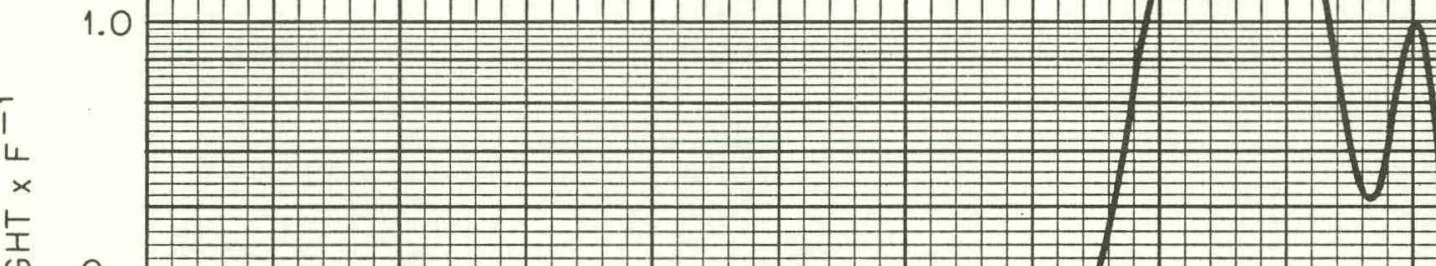

0.1

0.2

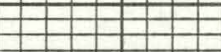

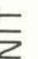

S

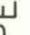

0.05

0.02

2 $15 \square$

$+2+$

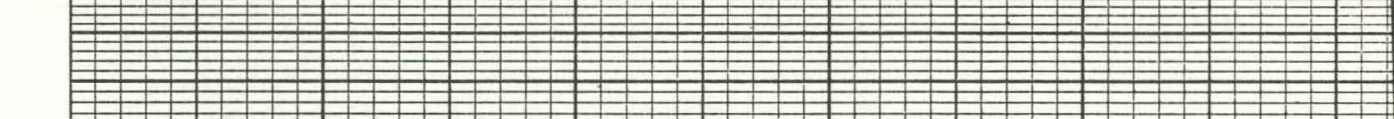

05

-

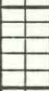




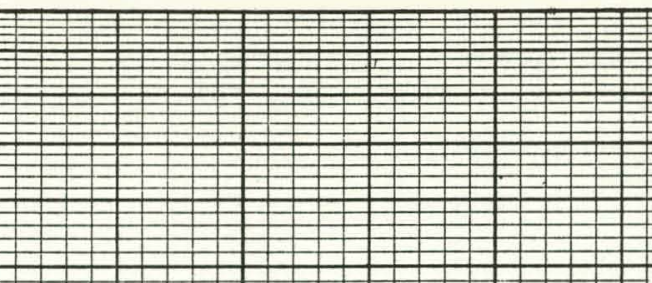

Fig. 33

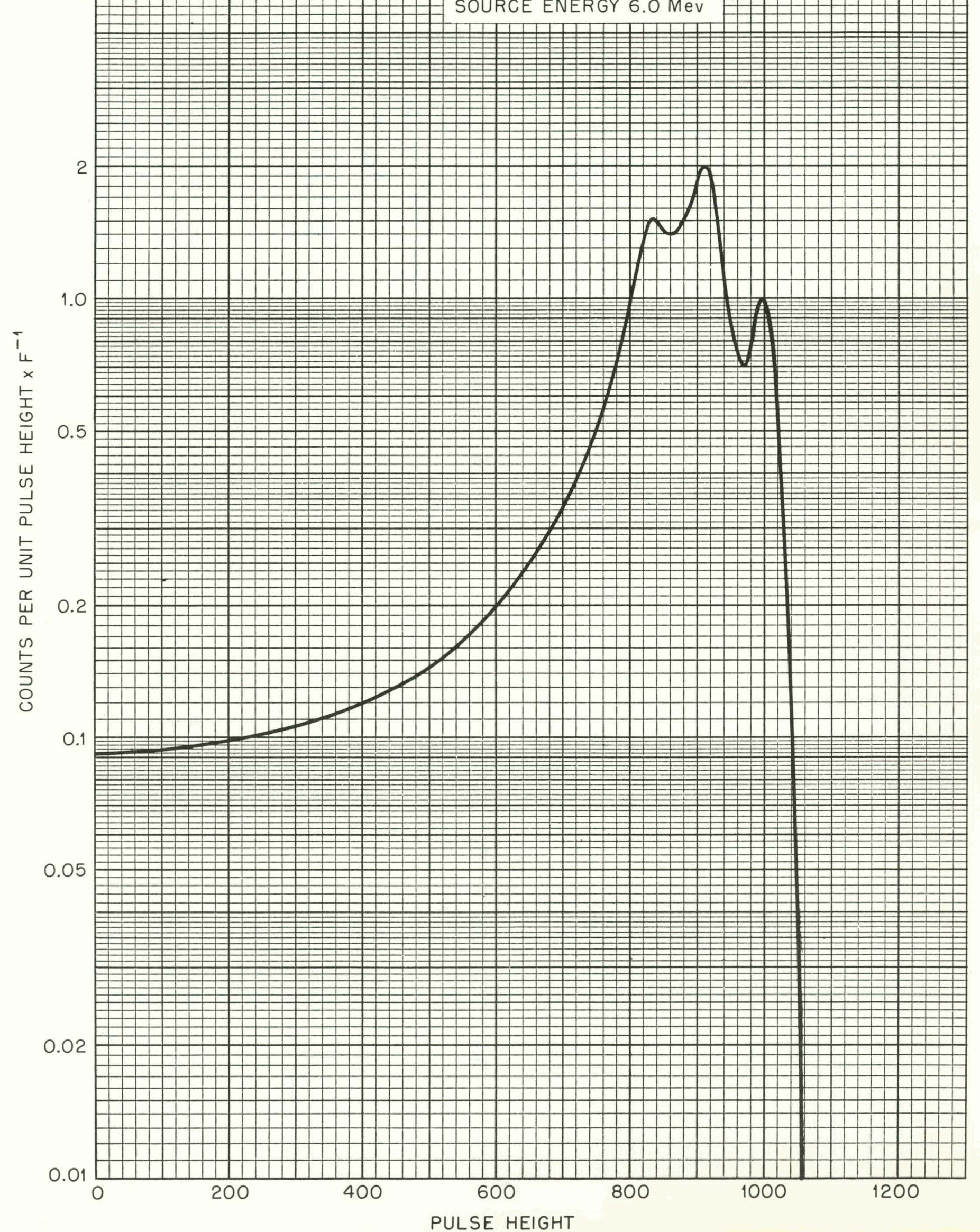




\author{
ORNL-3169 \\ UC-34 - Physics \\ TID-4500 (16th ed. Rev.)
}

IVTERNAL DISTRIBUIION

1. C. E. Larson
2. Biology Library
3. Health Physics Library
4-6. Central Research Library
7. Reactor Experimental
8ngineering Library
8-52. Laboratory Records
53. Laboratory Records, ORNL R.C.
54. A. M. Welnberg
55. R. G. Jordan (Y-12)
56. J. P. Murray (K-25)
57. J. A. Swartout
58. W. H. Jordan
59. E. P. Blizard
60. D. Phillips
61. M. J. Skinner
62. P. R. Bell
63. T. V. Blosser
64. A. R. Brosi
65. V. R. Cain
66. A. D. Callihan
67. G. T. Chapman
68. G. deSaussure
69. L. Dresner

$\begin{array}{ll}\text { 70. } & \text { E. Eichler } \\ \text { 71. } & \text { J. F. Emery } \\ \text { 72. } & \text { R. Gwin } \\ \text { 73. } & \text { K. M. Henry } \\ \text { 74. } & \text { I. B. Holland } \\ \text { 75. } & \text { N. R. Johnson } \\ \text { 76. } & \text { B. H. Kettelle } \\ \text { 77. T. A. Love } \\ \text { 78. W. S. Lyon } \\ \text { 79. F. C. Maienschein } \\ \text { 80. R. K. McGowan } \\ \text { 81. A. Meyer } \\ \text { 82. F. J. Muckenthaler } \\ \text { 83. R. B. Murray } \\ \text { 84. R. W. Peelle } \\ \text { 85. R. I. Robinson } \\ \text { 86. } \text { P. H. Stelson } \\ \text { 87-136. C. D. Zerby } \\ \text { 137. } \text { W. Zobel } \\ \text { 138. P. F. Gast (consultant) } \\ \text { 139. R. A. Charpie (consultant) } \\ \text { 140. G. Young (consultant) } \\ \text { 141. R. F. Taschek (consultant) } \\ \text { 142. T. J. Thompson (consultant) }\end{array}$

\title{
EXTERIVAI DISTRIBUTION
}

143-146. M. E. Bunker, B. J. Dropesky, M. A. Van Dilla, and R. B. Day; Ios Alamos Scientific Laboratory, Los Alamos, New Mexico

147. D. J. Horen; Lawrence Radiation Laboratory, Berkeley, Califormia

148-150. H. I. West, Jr., R. Hester (Room 114, Bldg. 131), and D. H. Davis; Lawrence Radiation Laboratory, Livermore, California

151. J。 B. Cumming; Brookhaven National Laboratory, Long Island, New York

152-153. C. S. Cook and J. P. Hurley (Code 945A); U.S. Naval Radiological Defense Laboratory, San Francisco 24, California

154. P. I. Heath; Phillips Petroleum Company, AED, Idaho Falls, Idaho

155. C. R. Pierce (Department of Nuclear Engineering and Science); Rensselaer Polytechnic Institute, Troy, New York

156. F. C. Schwenk; Space Nuclear Propulsion Office, USAEC, Washington 25 , D. C.

157. J。W. Keller (Attn: M-RP-N); NASA, Marshall Space Flight Center, Huntsville. Alabama

158-789. Given distribution as shown in TID-4500 (16th ed., Rev.) under Physics category ( 75 copies - OTS) 